San Jose State University

SJSU ScholarWorks

Master's Theses

Master's Theses and Graduate Research

1994

\title{
A survey of interdisciplinary activity between occupational therapists and speech-language pathologists in the evaluation and treatment of adults with dysphagia
}

Frieda Kristin Weiss

San Jose State University

Follow this and additional works at: https://scholarworks.sjsu.edu/etd_theses

\section{Recommended Citation}

Weiss, Frieda Kristin, "A survey of interdisciplinary activity between occupational therapists and speechlanguage pathologists in the evaluation and treatment of adults with dysphagia" (1994). Master's Theses. 881.

DOI: https://doi.org/10.31979/etd.ksms-jd2e

https://scholarworks.sjsu.edu/etd_theses/881

This Thesis is brought to you for free and open access by the Master's Theses and Graduate Research at SJSU ScholarWorks. It has been accepted for inclusion in Master's Theses by an authorized administrator of SJSU ScholarWorks. For more information, please contact scholarworks@sjsu.edu. 


\section{INFORMATION TO USERS}

This manuscript has been reproduced from the microfilm master. UMI films the text directly from the original or copy submitted. Thus, some thesis and dissertation copies are in typewriter face, while others may be from any type of computer printer.

The quality of this reproduction is dependent upon the quality of the copy submitted. Broken or indistinct print, colored or poor quality illustrations and photographs, print bleedthrough, substandard margins, and improper alignment can adversely affect reproduction.

In the unlikely event that the author did not send UMI a complete manuscript and there are missing pages, these will be noted. Also, if unauthorized copyright material had to be removed, a note will indicate the deletion.

Oversize materials (e.g., maps, drawings, charts) are reproduced by sectioning the original, beginning at the upper left-hand corner and continuing from left to right in equal sections with small overlaps. Each original is also photographed in one exposure and is included in reduced form at the back of the book.

Photographs included in the original manuscript have been reproduced xerographically in this copy. Higher quality 6" x 9" black and white photographic prints are available for any photographs or illustrations appearing in this copy for an additional charge. Contact UMI directly to order.

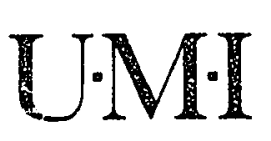

University Microfilms Internationa!

A Bell \& Howell information Company 300 North Zeeb Road. Ann Arbor. MI 48106-1346 USA

$313 / 761-4700 \quad 800 / 521-0600$ 


\section{.}

$\cdots$ 
Order Number 1959064

A survey of interdisciplinary activity between occupational therapists and speech-language pathologists in the evaluation and treatment of adults with dysphagia

Weiss, Frieda Kristin, M.S.

Sar Jose State University, 1994

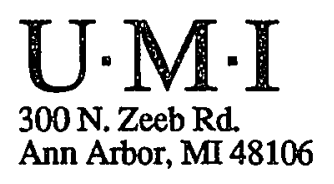





\title{
A SURVEY OF INTERDISCIPLINARY ACTIVITY BETWEEN OCCUPATIONAL THERAPISTS AND SPEECH-LANGUAGE PATHOLOGISTS IN THE EVALUATION AND TREATMENT OF ADULTS WITH DYSPHAGIA
}

\author{
A Thesis \\ Presented to \\ The Faculty of the Department of Occupational Therapy \\ San Jose State University \\ In Partial Fulfillment \\ of the Requirements for the Degree \\ Master of Science
}

By

Frieda Kristin Weiss, O.T.R.

August, 1994 
(C) 1994

Frieda Kristin Weiss

\section{ALL RIGHTS RESERVED}


APPROVED FOR THE DEPARTMENT OF OCCUPATIONAL THERAPY

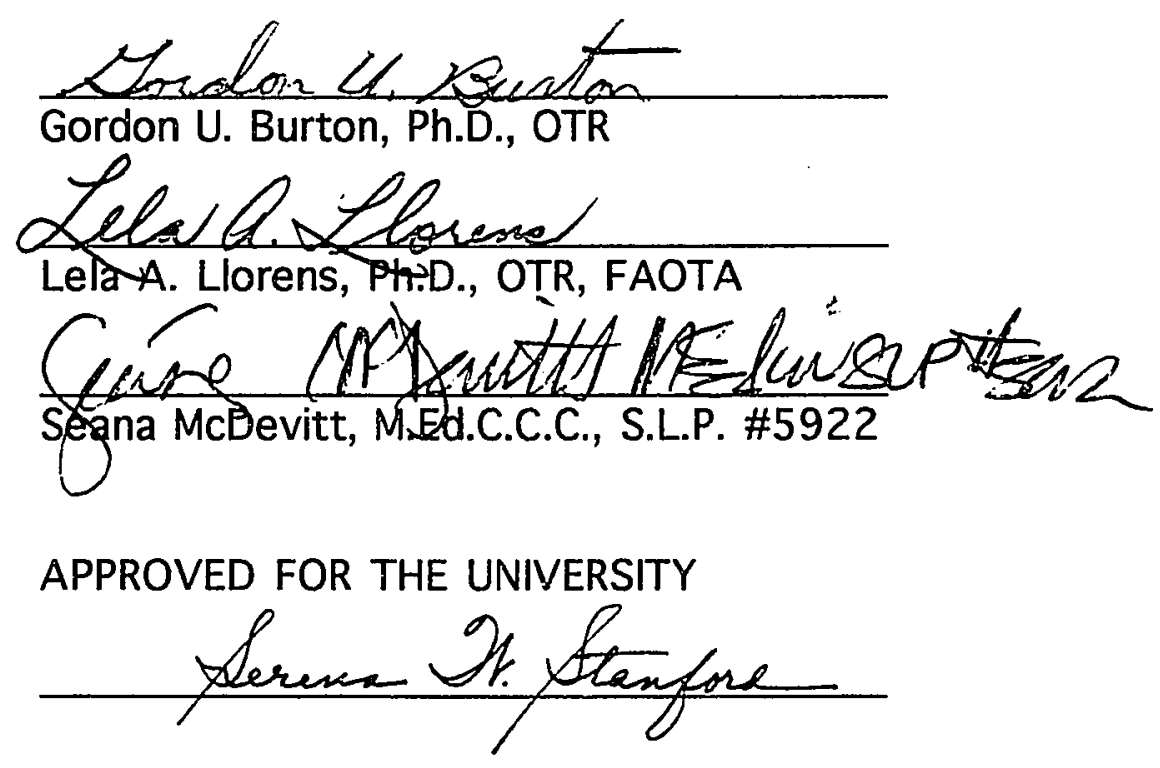




\begin{abstract}
A SURVEY OF INTERDISCIPLINARY ACTIVITY BETWEEN OCCUPATIONAL THERAPISTS AND SPEECH-LANGUAGE PATHOLOGISTS IN THE EVALUATION AND TREATMENT OF ADULTS WITH DYSPHAGIA

by

Frieda K. Weiss

A survey was conducted examining the interdisciplinary activities and roles of occupational therapists (OTs) and speech-language pathologists (SLPS) in the management of adults with dysphagia. A questionnaire was sent to 156 OTs and SLPs working in California acute rehabilitation facilities.

The results indicated that over half of the rehabilitation facilities employed speech-language pathology (SLP) as the primary discipline and $39 \%$ utilized an occupational therapy (OT)/SLP team approach in dysphagia case management. While many of the roles in dysphagia management were shared by OTs and SLPS, bedside evaluations and videofluoroscopies were assigned most frequently to SLP and feeding and positioning intervention to OT. The majority of OTs and SLPs found their interdisciplinary relations to be harmonious and valuable. Implications for this study include the need for occupational therapists to further clarify their clinical and educational role in dysphagia intervention.
\end{abstract}




\section{ACKNOWLEDGEMENTS}

I would like to express my gratitude to Gordon U. Burton, Ph.D., OTR, Seana McDevitt, M.S., SLP, and Lela Llorens, Ph.D., OTR, FAOTA for not only their editorial guidance and support but also their genuine interest and encouragement which inspired me to complete this thesis. I especially would like to thank Seana who invested a tremendous amount of her time and energy participating in this process and who will always represent "the ultimate team player" to me.

I would also like to thank the occupational therapists and speech-language pathologists who took the time and interest to participate in this research study, many of whom attached notes to the questionnaire acknowledging the timeliness and significance of this study and specifically requesting copies of the results.

And lastly, I would like to extend my loving gratitude to my mother who took the time to carefully read my proposal and provide encouragement, to my grandfather, without whose support I would not have had this opportunity, and especially, to my friend and partner Nathaniel Roberts, who believed in me and provided constant support and enthusiasm through the ebb and flow of this process.

I thank you all from my heart. 


\section{TABLE OF CONTENTS}

\section{Page}

Abstract...

iii

Acknowledgements..

iv

Chapter 1

INTRODUCTION

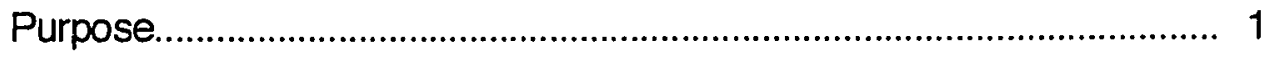

Statement of the Problem.......................................................... 1

Objectives...................................................................................... 3

Questions.................................................................................. 4

Definitions......................................................................................... 5

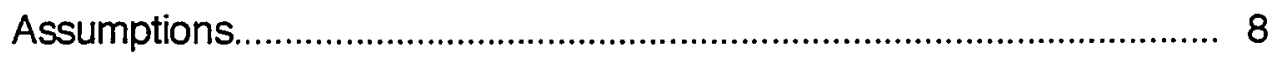

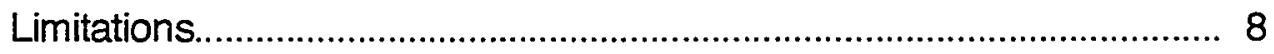

Significance of the Study....................................................... 9

Chapter 2

REVIEW OF THE LITERATURE

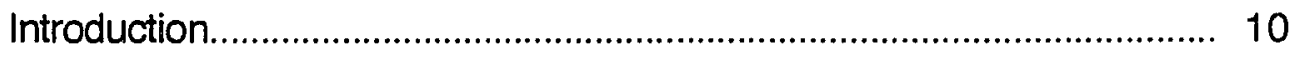

Dysphagia Intervention and the Model of Human

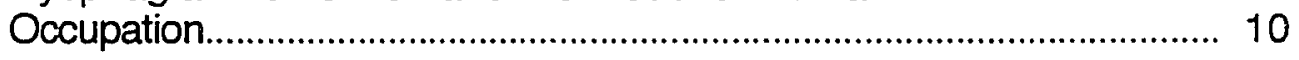

Principles of Interdisciplinary Practice .......................................... 11

Role of Occupational Therapy in the Area of Dysphagia................. 12

Role of Speech-Language Pathology in the Area of Dysphagia............................................................................................. 14

Interdisciplinary Team Roles in Dysphagia Management............... 17 
Efficacy of Interdisciplinary Team Approach to

Dysphagia

Interdisciplinary Activities between Occupational

Therapists and Speech-Language Pathoiogists..

Summary.

Chapter 3

DESIGN AND METHODOLOGY

Design of the Study.

26

Research Questions.. 26

Population and Sample. 27

Description of Data Gathering Instrument. 27

Procedure 28

Statistical Technique 29

Chapter 4

\section{DATA PRESENTATION AND RESULTS}

Questionnaire Returns.

What are the demographics of the occupational therapists and speech-language pathologists surveyed?.

What are the educational levels and backgrounds of the occupational therapists and speech-language pathologists surveyed?

Do C.A.F.F. accredited and/or N.A.R.F. membered

California rehabilitation facilities utilize an interdisciplinary team approach to dysphagia management?

How do these facilities delineate the roles of the occupational therapists and speech-language pathologies in the evaluation and intervention of dysphagia?. 
Is there a perception of role conflict or role

consonance among the occupational therapists and

speech-language patholgists surveyed?

Is an interdisciplinary approach to dysphagia

perceived to be of value for intervention?.

55

Other relevant data.

58

\section{Chapter 5}

SUMMARY, PROFESSIONAL IMPLICATIONS,

AND CONCLUSIONS

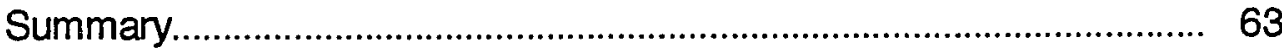

Professional Implications........................................................ 69

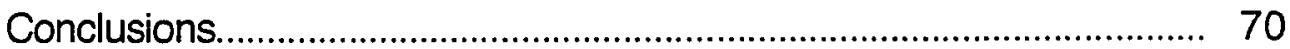

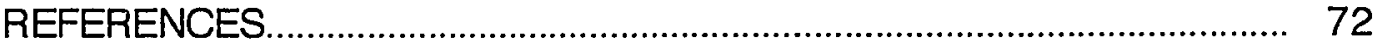

APPENDICES

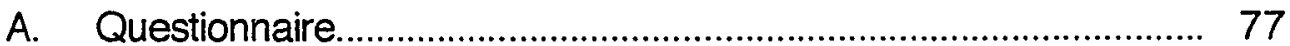

B. Letter of Consent................................................................ 83

C. Introductory Letter.............................................................. 86

D. Postcard Reminder............................................................... 89 


\section{LIST OF TABLES}

Table

page

1 Age of Occupational Therapy and Speech-Language Pathology Respondents.

2 Reported Years of Practice in Occupational Therapy and Speech-Language Pathology.

3 Combined Locations of College Education in Occupational Therapy and Speech-Language Pathology.

4 Places of Skill Development in Dysphagia Management.

5 Do Respondents want to see a Team Developed?.

6 Role Delineation in Dysphagia Case Management for the Facilities that use an Interdisciplinary Team Approach.

7 Role Delineation in Dysphagia Case Management for the Facilities that don't use an OT/SLP Interdisciplinary Team Approach.

8 Role Delineation in Dysphagia Case Management for all Facilities

9 OT and SLP Respondents Reporting Factors Contributing to Role Conflict.

10 OT and SLP Respondents Reporting Factors Contributing to Role Harmony.

11 Level of Value Attributed to OT/SLP Interdisciplinary Relations in the Area of Dysphagia. 56

12 Reasons Attributed to Very Valuable or Moderately Valuable Interdisciplinary OT/SLP Relations in Dysphagia Management.

13 Reasons Attributed to Minimal Value or no value placed on Interdisciplinary OT/SLP Relations in Dysphagia Management. 
14 OT and SLP Perceived Areas of Unique Expertise Contributing to Dysphagia Intervention. 


\section{LIST OF FIGURES}

Figures page

1 Reported Number of Occupational Therapists at Rehabilitation Facilities............................................................... 35

2 Reported Number of Speech-Language Pathologists at Rehabilitation Facilities............................................................... 36

3 Highest Level of Education of Occupational

Therapy Respondents......................................................................... 37

$4 \quad$ Highest Level of Education of Speech-Language

Pathology Respondents........................................................................ 38

5 Occupational Therapy College Course Hours

in Dysphagia........................................................................................... 42

6 Speech-Language Pathology College Course

Hours in Dysphagia ........................................................................... 43

7 Discipline(s) Responsible for Primary Evaluation and Treatment of Patients with Dysphagia.................................... 45 


\section{CHAPTER 1}

\section{INTRODUCTION}

\section{Purpose}

The purpose of this study was to examine the interdisciplinary activities and roles of occupational therapists and speech-language pathologists in the evaluation and treatment of adult patients with dysphagia and to identify issues and questions related to the overlapping roles between these disciplines.

\section{Statement of the Problem}

Only in the last twenty years has attention by the medical and allied health professions been focused on the diagnostic and treatment components of adult populations with swallowing disorders. This has largely been due to the increase in the percentage of adults over the age of 65 with swallowing disorders and the medical and clinical advances in the diagnosis and intervention of dysphagia within a variety of populations and disorders (Martens, Cameron, \& Simonsen, 1990). According to the U.S. Bureau of Census, an estimated 31 million people, $12.6 \%$ of the total population, are over the age of 65 (Lubinski \& Frattali, 1993). Donner (1986) reported that dysphagia can afflict any age group, but is most often seen in older persons. Although an escalation in research and clinical programs has occurred in the past 10 years, dysphagia rehabilitation with adult populations is a field still in its infancy (Martens, Cameron, \& Simonsen, 1990).

Medicare guidelines have recognized both occupational therapists (OTs) and speech-language pathologists (SLPS) as service providers for dysphagic adults (Mody \& Nagai, 1990). Yet the definition and delineation of their roles 
with dysphagic patients remains blurred and variable as described by the few articles found on interdisciplinary dysphagia team management with adult populations (Bach et al., 1989; Edwards \& Hanley, 1989; Hynak-Hanikinson et al., 1984; Jones \& Altschuler, 1987; Mody \& Nagai, 1990). Only in the past 7 years have the national associations of occupational therapy and speechlanguage pathology addressed the specific roles of each profession in the evaluation and treatment of dysphagia through formal reports and position papers (American Occupational Therapy Association, 1989; Enstrom et al., 1987). Unfortunately, these reports, as well as published literature from both professions, have failed to address thoroughly the role and significance that interdisciplinary activities play in the quality management of adult patients with dysphagia. They have also failed to explore the difficulties that may arise from increasing fiscal constraints in the reimbursement process, such as potential denial of dysphagia services from OT and SLP assessed as duplicable.

Several articles and studies from other disciplines, such as nutritional services, nursing, and otolaryngology, have described the benefits and effectiveness of an interdisciplinary team approach to the management of dysphagia. A number of articles have pointed to the increasing trend toward interdisciplinary or multidisciplinary team approaches in a variety of medical and clinical settings (Bach et al., 1989; Emick-Herring \& Wood, 1990; HynakHankinson et al., 1984; Jones \& Altschuler, 1987). Yet these authors fail to address how the various disciplines are prepared to meet this trend programmatically, educationally, and professionally.

In no other area of medical and clinical symptomology is the combined, unique backgrounds and expertise of occupational therapy and speech- 
language pathology warranted than in the complex, often life threatening cases of patients/clients with dysphagia. This author has been exposed to a variety of health care professionals and medical settings in which the management of dysphagia has been either the responsibility of an interdisciplinary team or of a specific discipline (namely, OT or SLP). Interdisciplinary conflict and territorialism have also been observed by this author and yet little has been written that addresses the need to evaluate and resolve these differences. Following a review of literature on interdisciplinary dynamics, Edwards and Hanley (1989) identified the need for research "regarding the degree and type of interdisciplinary activity between occupational therapists and speechlanguage pathologists" (p. 375) and including "philosophical differences that undermine interdisciplinary management of health problems" (p. 385). It is hoped that this study will generate a beginning body of data which will stimulate further questions, hypotheses, and research into the area of interdisciplinary dysphagia management.

\section{Objectives}

The objectives of this study were:

1) To determine the demographic backgrounds of the occupational therapists and speech-language pathologists surveyed.

2) To determine the educational levels and backgrounds of the occupational therapists and speech-language pathologists surveyed.

3) To determine how many California rehabilitation facilities which are accredited by the Commission on Accreditation of Rehabilitation Facilities (C.A.R.F.) and/or are members of the National Association of Rehabilitation 
Facilities (N.A.R.F.), utilize an interdisciplinary team approach to dysphagia intervention.

4) To determine how these facilities delineate the roles of occupational therapists and speech-language pathologists in the evaluation and treatment of dysphagia.

5) To determine if role conflict or role consonance exists among the occupational therapists and speech-language pathologists in the dysphagia program.

6) To determine if the occupational therapists and speech-language pathologists surveyed value an interdisciplinary approach to dysphagia.

\section{Questions}

The research questions to be answered in this study were:

1) What are the demographics of the occupational therapists and speechlanguage pathologists surveyed?

2) What are the educational levels and backgrounds of the occupational therapists and speech-language pathologists surveyed?

3) What percentage of C.A.R.F. accredited and/or N.A.R.F. membered California rehabilitation facilities utilize an interdisciplinary team approach to dysphagia intervention?

4) How do these facilities delineate the roles of the occupational therapists and speech-language pathologists in the evaluation and intervention of dysphagia?

5) Is there a perception of role conflict or role consonance among the occupational therapists and speech-language pathologists surveyed? 
6) Is an interdisciplinary approach to dysphagia perceived to be of value for intervention?

\section{Definitions}

Adults with dysphagia: Refers to a variety of diagnoses in the age range of 18 to $100+$ including neurological disorders such as cerebral vascular accident, traumatic brain injury, Parkinson's disease, Alzheimer's disease, spinal cord injury, etc., oncological disorders such as head and neck cancer with surgical intervention, and unspecified conditions such as dementia or aging which can affect the swallowing function.

C.A.R.F.: Commission on Accreditation of Rehabilitation Facilities.

Dysphagia: Greek derivative "dys" meaning difficult or disordered and "phagein" meaning to eat (Roueche, 1980). "This diagnosis is used to indicate a disturbance in the normal transfer of food from the oral cavity through the pharynx and esophagus to the stomach" (Roueche, 1980, p. 1). See literature review for definitions by OT and SLP associations.

Interdisciplinary: "Combining or involving two or more academic disciplines" (Stein, Hauck, \& Su, 1984, p. 694). "Interdisciplinary team is defined as individuals sharing in the decision-making and goal-setting processes through face-to-face contact. Such a team promotes an intermingling of professional identities and activities to achieve the agreed upon goals." (Bair, 1983, p. 11) Interdisciplinary activities: Refers to the specific interactions and collaborative efforts of the occupational therapists and speech-language pathologists in the evaluation and treatment of dysphagic adults.

Multidisciplinary: "Multidisciplinary team is defined as one or two individuals acting as the core communication intermediaries in directing and planning the 
overall activities of ancillary members who may or may not meet with other team members." (Bair, 1983, p. 11)

N.A.R.F.: National Association of Rehabilitation Facilities.

Occupational Therapist: An occupational therapist is a nationaliy cerifified and/or state licensed health care professional who has completed a bacclaureate and/or graduate level occupational therapy program and who provides services."to those individuals whose abilities to cope with tasks of living are threatened or impaired by developmental deficits, the aging process, poverty and cultural differences, physical injury or illness, or psychological and social disability" (The American Occupational Therapy Association, 1986, p. II.1).

Occupational Therapy: "Occupational therapy is the art and science of directing man's participation in selected tasks to restore, reinforce and enhance performance, facilitate learning of those skills and functions essential for adaptation and productivity, diminish or correct pathology, and to promote and maintain health. Reference to occupation in the title is in the context of man's goal-directed use of time, energy, interest, and attention. Its fundamental concern is the capacity, throughout the life span, to perform with satisfaction to self and others those tasks and roles essential to productive living and to the mastery of self and the envircnment" (The American Occupational Therapy Association, 1986, p. Il.1).

Role delineation: Refers to the defined duties and responsibilities of occupational therapists and speech-language pathologists related to the evaluation and treatment of dysphagia and established by the surveyed therapists and/or the facilities where they work. 
Role conflict: Refers to any disagreement, discord, or feelings of territorialism between occupational therapists and speech-language pathologists related to their roles in the dysphagia program.

Role consonance: Peiers to agreement, concord, and harmony between occupational therapists and speech-language pathologists related to their roles in the dysphagia program.

Role delineation: Refers the the defined duties and responsibilities of occupational therapists and speech-language pathologists related to the evaluation and treatment of dysphagia and established by the surveyed therapists and/or the facilities where they work.

Speech-language pathologist: Speech-language pathologists are professionals who "hold either the master's or doctoral degree, the Certificate of Clinical Competence of the American Speech-Language-Hearing Association, and state license where applicable" (American Speech-Language-Hearing Association, 1990, p. 1). "These professionals identify, assess, and provide treatment for individuals of all ages with communication disorders" (p. 1). Speech-language pathology: According to the American SpeechLanguage-Hearing Association's Scope of Practice (1990) the practice of speech-language pathology includes: "1) Screening, identifying, assessing, and interpreting, diagnosing, rehabilitating, and preventing disorders of speech (e.g., articulation, fluency, voice) and language, 2) screening, identifying, assessing, and interpreting, diagnosing, and rehabilitating disorders of oralpharyngeal function (e.g., dysphagia) and related disorders, 3) screening, identifying, assessing and interpreting, diagnosing, and rehabilitating cognitive/communication disorders, 4) assessing, selecting and developing 
augmentative and alternative communication systems and providing training in their use, 5) providing aural rehabilitation and related counseling services to hearing impaired individuals and their families, 6) enhancing speech-language proficiency and communication effectiveness (e.g., accent reduction), and 7) screening of hearing and other factors for the purpose of speech-language evaluation and/or the initial identification of individuals with other communication disorders" (pp. 1-2).

Value: The relative worth, merit, usefulness, meaning, or import attributed to interdisciplinary relations between occupational therapists and speechlanguage pathologisisis in the area of dysphagia.

\section{Assumptions}

The assumptions held by the researcher were:

1) A significant number of occupational therapists and speech-language pathologists from California rehabilitation facilities would respond to this survey.

2) A significant number of rehabilitation facilities follow an interdisciplinary team approach toward dysphagia.

\section{Limitations}

The limitations of the study were:

1) To ensure a large sample, the occupational therapists and speech-language pathologists were not randomly selected which limits the generalizability of the results.

2) The therapists surveyed included only those who work in rehabilitation facilities in the state of California which limits the generalizability of the results. 
3) Selection of the specific questions asked on the questionnaire may reflect bias on the part of this researcher and may have resulted in other relevant information being missed.

4) The questionnaire included a majority of close-ended questions which may have prevented a range of potential responses from being obtained.

5) The study sought only to obtain information and potentially identify relationships between certain variables; therefore, causation cannot be inferred.

\section{Significance of this Study}

With the growing trend of interdisciplinary dysphagia teams in adult rehabilitation facilities, the call for more careful examination into the interdisciplinary activities, roles, and relations between occupational therapists and speech-language pathologists becomes crucial. As the population becomes weighted in the 65 and older age groups (Lubinski \& Frattali, 1993), the number of dysphagia cases will increase as will the need for professionals trained in dysphagia intervention. This need is already facing a significant shortage of allied health professionals in many settings.

The many facets of swallowing and eating disorders can best be addressed by a number of professional backgrounds and approaches. Occupational therapists and speech-language pathologists are both trained in specific skills which uniquely contribute to the rehabilitation of a dysphagic patient. Yet in a time of continuing health care cuts and reimbursement conflicts, there is a need to evaluate how these professions delineate their roles in dysphagia rehabilitation and what issues exist, if any, which interfere with interdisciplinary relations. 


\section{CHAPTER 2 \\ REVIEW OF THE LITERATURE \\ Introduction}

The following literature review includes a description of Kielhofner's Model of Human Occupation (1983) as a frame of reference for dysphagia intervention, principles of interdisciplinary practice, the role of occupational therapy in the area of dysphagia, the role of speech-language pathology in the area of dysphagia, interdisciplinary team roles in dysphagia management, efficacy studies of the interdisciplinary approach to dysphagia, and lastly, interdisciplinary activities between occupational therapists and speechlanguage pathologists.

\section{Dysphagia Intervention and the Model of Human Occupation}

The process of swallowing and eating involves a multitude of components which require assessment of the individual as an open system. In the Model of Human Occupation, Kielhofner defined an open system as "a composition of interrelated structures and functions organized into a coherent whole that interacts with an environment" $(1983$, p. 4). An assumption of this model is that a system cannot be assessed nor understood in isolation from its particular environment (Kielhofner, 1983).

Kielhofner (1983) described the environment of the individual as those objects, events, and people with which the person comes into contact. Evaluating the myriad of "skill constituents" and functions involved in swallowing such as oral-pharyngeal sensation, motor strength, range of motion, and praxis without consideration of the environmental and cultural components 
of the individual's eating skills and habits, would be adhering to a reductionistic frame of reference.

Kielhofner (1983) advocated basing clinical judgements on model or network description which involves gathering thorough information on the patient's numerous conditions in the system's environment. In the area of dysphagia evaluation and treatment for adult populations, many of these clinical judgements involve networking between more than one discipline to gather all of the essential information required for decisions such as safe oral intake. Approaching the patient as an open system and as a whole organism involves the collaboration of several disciplines in the cases of dysphagia intervention and management.

\section{Principles of Interdisciplinary Practice}

Numerous articles have been published from a variety of disciplines which advocate the development of collaborative relationships among the health professions in the management of patient care (Bassoff, 1983; Darling \& Ogg, 1984; Harris, Saunders, \& Zasorin, 1976; Ivey, Brown, Teske, \& Silverman, 1987). Ivey, Brown, Teske, and Silverman (1987) presented a model for teaching about interdisciplinary practice in health care settings which closely parallels some basic principles of Kielhofner's (1983) Model of Human Occupation. The organizing principle of this model is a holistic frame of reference which views the patient/client as a person, not a given health problem. The value of interdisciplinary team work to the enhancement of patient care includes a collaboration of varied backgrounds, approaches, and skills, particularly in health care cases which are chronic and complex. 
Ivey, Brown, Teske, and Silverman (1987) described forms of interdisciplinary practice which lie along a continuum of professional autonomy. Along this continuum, parallel practice evolves into an interdisciplinary health care team following stages of collaboration, consultation, coordination and multidisciplinary practice. Difficulties which may arise during this process may stem from role definition, role negotiation, and role clarification. Darling and Ogg (1984) described the basic requirements for initiating an interdisciplinary process as common value commitments, interpersonal communication skills, similarity between disciplines, and low level of perceived threat. The role of occupational therapy within a team of health care professionals has been largely ignored in the existing professional and educational literature. The remainder of this literature review will attempt to specifically address the role of occupational therapy and speech-language pathology in the parallel practice and interdisciplinary practice of dysphagia intervention.

Role of Occupational Therapy in the Area of Dysphagia

The profession of occupational therapy (OT) has been largely focused on its role in the evaluation and treatment of swallowing/feeding disorders in the developmentally disabled and pediatric populations as represented by the wealth of published articles and studies over the past 30 years. Silverman and Elfant (1979) were the first occupational therapists (OTs) to publish an article in the American Journal of Occupational Therapy describing the role of OT in the evaluation and treatment of dysphagia for the adult. In the following 12 years a handful of books and brief articles were published defining the process of dysphagia evaluation and management for a variety of adult populations 
(Boggis, 1985; Cinerney, Cantieri, \& Pannell, 1986; Cloke \& Miller, 1989;

Cromwell, 1986; Groher, 1984; Roueche, 1980; Stallons, 1987).

The outcome of this growing literature resulted in a call for a position paper by the American Occupational Therapy Association (AOTA). The following statements were defined by the AOTA Commission on Practice in 1989: "eating is a significant performance area of daily living skills throughout a person's life," "feeding is the process of getting food to the mouth, while eating is the process of moving food from the mouth to the stomach," and refers to eating/feeding as "the skill and performance of sequentially feeding oneself, including sucking, chewing, swallowing, and the manipulation of appropriate utensils" (p. 805). The position paper also briefly described the areas of focus which OT addresses in the evaluation and treatment of "eating dysfunction" and encouraged advanced education and clinical practice prior to providing these services. The following sentence was the only mention of interdisciplinary team relations in the management of dysphagia: "Through collaboration with other professionals, occupational therapists promote maximal independence in all components of eating" (p. 805).

The most recent articles to be published in the occupational therapy literature included a case report for an adult with traumatic brain injury (Yuen \& Hartwick, 1992) and descriptions of clinical assessment methods and treatment approaches for adult patients with dysphagia (Avery-Smith, Dellarosa, \& Rosen, 1992; Avery-Smith \& Dellarosa, 1993). Yuen and Hartwick (1992) defined the role of the occupational therapist in the treatment of persons with dysphagia as follows: "diet manipulation, oral desensitization through sensory stimulation, muscle reeducation, cognitive-perceptual retraining, proper positioning, 
structuring of the feeding environment, prescription and fabrication of adiapted feeding devices, or a combination of these procedures" (p. 943). Avery-Smith and Dellarosa (1993) and Avery-Smith, Dellarosa, and Rosen (1992) described the following subskill areas for documenting efficacy of occupational therapy interventions: Alertness and orientation, cognitive impairments and behavioral dysregulation, positioning and proximal control, self-feeding, oral and pharyngeal sensory disorders, and oral and pharyngeal movement disorders. These authors advocated more research into these subskill areas and the overall effects of all deficit areas commonly seen in patients with brain injury.

Role of Speech-Language Pathology in the Area of Dysphagia Among the growing literature published over the past 20 years by the allied health professions, speech-language pathologists (SLPs), spurred by Jerilyn A. Logemann, Ph.D., have been the leaders in the research and clinical education of swallowing disorders and specific diagnostic and therapeutic procedures among a variety of adult populations (Logemann, 1983, 1985, 1986, 1987; Logemann \& Bytell, 1979). Two major references on the evaluation and treatment of patients with oropharyngeal dysphagia have been authored by speech-language pathologists (Groher, 1984; Logemann, 1983). In recent years, the role of speech-language pathologists in the evaluation, management, and treatment of patients with dysphagia has been recognized by the Joint Commission for Accreditation of Healthcare Organizations, the Health Insurance Association of America, the National Institutes of Health, the U.S. Department of Health and Human Services, and the American Academy of Neurology (Erlichman, 1989; Miller \& Groher, 1993). 
Erlichman (1989) described the philosophical rationale for SLP's primary role in dysphagia assessment and intervention as follows:

Proponents for employing speech-language pathologists in managing patients with dysphagia argue that the academic and clinical preparation of speech-language pathologists makes them particularly well prepared to deal with problems of communication and swallowing. Speech-language pathologists are trained to perform detailed oral-peripheral examinations, including assessments of oral (mouth) and pharyngeal (throat) sensorimotor systems....Providing therapy for dysphagia is a logical extension of speech and language pathology since treatment of communication disorders includes stimulation of muscle groups common to both speech and swallowing. (p. 3) Logemann (1989) also emphasized the unique role of speech and language pathology in dysphagia intervention as follows:

Swallowing, phonation/articulation, and respiration are the three major functions of the upper aerodigestive tract. If we are to understand motor control of the upper aerodigestive tract during normal and abnormal respiration and speech production, we must also understand control of deglutition as it interacts with the other two functions....If two separate rehabilitation professionals are working in the upper aerodigestive tract to restore/improve function, one in speech and one in swallowing, we will never understand the possible complementary or contradictory effects of specific exercise or therapy programs. (p. 9) 
Logemann also stressed the economic benefits for the patient in utilizing a rehabilitation professional who can work on speech and swallowing simultaneously.

In 1983 the American Speech-Language-Hearing Association formed an Ad Hoc Committee on dysphagia with the purpose of defining the role of the speech-language pathologist (SLP) in the area of dysphagia (Enstrom et al., 1987). They defined dysphagia as "a swallowing disorder characterized by difficulty in oral preparation for the swallow or in moving material from the mouth to the stomach" (p. 57). They thoroughly outlined the guidelines for intervention in dysphagia, the guidelines for clinical preparation, the research needs, and the interprofessional activity needs.

The Ad Hoc Committee cited a 1985 Omnibus survey in which $35 \%$ of SLPs were found to be involved in the delivery of dysphagia treatment to both communicatively disordered and noncommunicatively disordered clients. These figures were updated by the American Speech-Language-Hearing Association (ASHA) in a 1988 Omnibus Survey indicating that $42.5 \%$ of SLP respondents reported they regularly serve a population of patients with swallowing disorders (Miller \& Groher, 1993).

The Ad Hoc Committee also stated that "the most prevalent model for care of dysphagia currently involved a speech-language pathologist who has chosen to become involved with dysphagia as dysphagia team coordinator" (p. 57). They distinctly identified the need for SLPs to work in close collaboration with an interdisciplinary dysphagia team which involved many diverse disciplines, including occupational therapy. In conclusion, this committee stressed the significant need "to develop a mechanism to foster 
written and verbal communication between the many professionals from diverse disciplines involved in the evaluation and rehabilitation of dysphagic individuals" (p. 58).

\section{Interdisciplinary Team Roles in Dysphagia Management}

Over the past fifteen years, literature on the interdisciplinary team approach to dysphagia has been represented by a number of medical and allied health professions. In 1982, Logigian edited a book entitled Adult Rehabilitation: A Team Approach for Therapists which included descriptions of the roles of occupational therapists, physical therapists, and speech-language pathologists in the rehabilitation of a variety of adult populations. The book recommended "the skilled intervention of the rehabilitation team" in the management of dysphagia for both neurologic and oncologic diagnoses (pp. 61, 291-292). It also recommended that with the development of an interdisciplinary dysphagia team and program, "the role of each team member should be clearly defined" (p. 292). Yet these roles remained undefined and undifferentiated by this book's authors.

In Rehabilitation Nursing (Emick-Herring \& Wood, 1990), a model dysphagia program from Younker Rehabilitation Center, Des Moines, lowa was described. The authors defined the specific roles of the OT and SLP involved in the dysphagia program as follows:

Speech and OT staff members provide patients with daily individual treatment sessions, whereas nursing, medical, and dietary team members do not. The speech pathologist's role includes instructing patients on specific drills, exercises, and compensation techniques to improve oral phase and pharyngeal phase swallowing disorders. 
Similarly, OT clinicians perform in-depth motor and sensory testing to assess for dysphagia involvement. They also implement stimulation techniques and exercises to promote more normal swallowing function, and they initiate and evaluate appropriate adaptive feeding utensils and equipment to optimize the patient's posture during mealtime. (p. 129) With this interdisciplinary team approach to dysphagia, the authors reported that more than $90 \%$ of the dysphagic patients at the Younker Rehabilitation Center become "at least partial oral eaters and drinkers" (p. 132).

Bach et al. (1989) described the role of each member in the integrated team approach to the management of patients with oropharyngeal dysphagia as defined by therapists who organized meetings in this area at the University Hospital of the University of Western Ontario. The team included the departments of occupational therapy, physical therapy, speech-language pathology, nutritional services, radiology, and a staff neurologist. The occupational therapist's role included a mealtime evaluation of feeding ánd swallowing difficulties and an assessment of the cognitive, perceptual, and upper extremity skills related to feeding and swallowing. The OT worked collaboratively with the physical therapist in evaluating the positioning needs of the patient for the required sitting position ior the modified barium swallow study. The speech-language pathologist evaluated the patient's "orofacial, velar, laryngeal, and pharyngeal functions" (p. 461), as well as the patient's ability to follow directions during the modified barium swallow study.

A multidisciplinary program entitled "Dysphagia Management and Treatment: The Team Approach," sponsored by the VA Medical Center, East Orange, New Jersey was described in the journal Nutritional Support Services 
(Hynak-Hankinson et al., 1984). Delineation of the clinical roles of the dysphagia team members was described. They recognized that roles may overiap "depending upon the institution, administrative policies, and/or level of expertise" (p. 36). They emphasized that "policies and procedures as developed by the Dysphagia Team can clearly delineate the role of each member to provide team efficiency and optimal patient care" (p. 36). In an attempt to differentiate the roles of OT and SLP in dysphagia intervention, these authors staied that "occupational therapists primarily work with dysphagic patients having problems with the first stage of swallowing" and act as "a consultant for adaptive feeding equipment" (p. 30). They also suggested that "muscular control is one of the overlapping areas between the occupational therapist and speech pathologist" (p. 30) and encourage consultation with one another to avoid duplication of services.

In a 1989 article, Lorman, a speech-language pathologist, described the delineation of OT and SLP roles in the dysphagia program developed at Akron City Hospital in Ohio state. She reported that the responsibility for swallowing therapy often fell to the speech-language pathologists due to their training in oral musculature rehabilitation, knowledge of the respiratory/phonatory system, ability to communicate with neurologically impaired patients, and the growing awareness of the cognitive features that interfere with safe swallowing. She also stated that the OT and SLP divided the dysphagia cases according to "traditional feeding versus swallowing boundaries" (p. 11) where the OT worked on self-feeding and the SLP worked on the oral and pharyngeal phases of swallowing. 
Penington and Krutsch (1990), from Mount Royal Hospital, Parkville, Victoria, Australia, advocated a "coordinated, expert, interdisciplinary approach" (p. 21) for the rehabilitation of patients with swallowing disorders. They described this approach as including a speech pathologist, nurse, dietician, physiotherapist, occupational therapist, and social worker as integral members of the swallowing team. They defined the speech pathologist's role as the key coordinator, diagnostician, and manager in the swallowing program. The role of the occupational therapist was described as facilitating the preoral phase of swallowing and at times, attending to orofacial therapy, relaxation, and posture.

The most current descriptive article on the development of a therapeutic feeding team in a rehabilitation setting was written by an interdisciplinary team which included nursing, dietary, occupational therapy, and speech-language pathology (Glenn, Araya, Jones, \& Liljefors, 1993). These authors describe the development of a standard set of defining characteristics and therapeutic processes associated with a patient's functional capacity to self-feed that can be implemented across clinical disciplines. Patients are referred by nursing after their initial assessment to occupational therapy for an extensive self-feeding evaluation. This self-feeding assessment includes information about components such as "positioning, utensil and finger use, meal setup and food item assembly, cognition, upper extremity function, perception, and apraxia" (p. 75). If the patient exhibits swallowing deficits, the nurse then refers him/her to speech-language pathology for further assessment. The speech-language pathologist determines whether a bedside dysphagia evaluation or a modified barium swallow (videofluoroscopy) is indicated. If a modified barium swallow study is conducted, a nurse, speech-language pathologist, and occupational 
therapist are present to view the study and the effect of compensatory techniques, and to provide suctioning for the patient if needed.

Glenn, Araya, Jones, and Liljefors (1993) concluded their article by presenting the positive outcomes noted since the implementation of their facility's therapeutic feeding team. These outcomes include early identification and thus intervention for patient's swallowing deficits, uniform rating systems for swallowing status, increased knowledge of swallowing deficits and therapeutic intervention by nursing, and lastly, improved communication across disciplines and greater respect for expertise and complementary skills.

\section{Efficacy of Interdisciplinary Team Approach to Dysphagia}

As evidenced by the aforementioned articles, there is a growing body of descriptive literature which is encouraging a move toward an interdisciplinary team approach for the management of dysphagia. Yet as discovered by Martens, Cameron, and Simonsen (1990), no quantitative research has been conducted which describes the efficacy of instituting a dysphagia treatment team. Therefore, the above researchers instituted a study to determine if a multidisciplinary dysphagia program would improve neurologically impaired patients' caloric intake and body weight, decrease the instances of aspiration pneumonia, or improve patients' feeding ability.

A convenience nonprobability sample of 31 patients were referred from a neurology/neurosurgery unit: 15 in the control group and 16 in the treated group. A time series design was used. The control group was managed according to the existing ward routine including recommendations for feeding patients by the physicians with input from the dieticians and nurses.

Subsequently, nursing staff attended a dysphagia training program, the treated 
group was assessed by the dysphagia team, and an individualized treatment program was designed for each patient. The two groups were then compared on the basis of deviation from their baseline weight and ideal energy intake, and the incidence of aspiration pneumonia. They found a statistically significant weight gain and increase in caloric intake among the treated group but no incidence of aspiration pneumonia among either group. They concluded that the institution of a multidisciplinary team in the management of dysphagia resulted in an increase in patients' weight and caloric intake.

\section{Interdisciplinary Activities between OT and SLP}

Only two articles were found which addressed the interdisciplinary activities between OTs and SLPs in the evaluation and treatment of adults with dysphagia. Mayuri Mody, an occupational therapist, and Jeanette Nagai, a speech-language pathologist, published the first article found which described a multidisciplinary approach to the development of competency standards and appropriate allocation for patients with dysphagia (1990). They briefly reviewed the history of dysphagia intervention among both professions, in which the first references to swallowing disorders for pediatric populations were found in 1931 for speech-language pathology (Travis) and 1956 for occupational therapy (Rood). They stated that "because feeding is a primary self-care activity, occupational therapists traditionally have played an active role in feeding programs" (p. 369) and "because the structures used for speech are also essential for swallowing, speech pathologists acquire a basic knowledge of deglutition" (p. 370).

Mody and Nagai (1990) also described a telephone survey which they conducted in Southern California of two undergraduate programs and one 
graduate program in occupational therapy. They reported finding that "although the course content may or may not specifically address the diagnosis and treatment of dysphagia, these three schools teach the primary skills needed to work with patients with this condition" and "address aspects of the anatomy and neurophysiology of swallowing" (p. 370). In a telephone survey conducted of four randomly chosen speech pathology programs in Southern California, they found three of the four provided some education specifically for dysphagia management.

Mody and Nagai (1990) addressed the need for competency standards for dysphagia management among OTS and SLPs and described the clinical preparation program developed at Cedars-Sinai Medical Center in Los Angeles, California. This program utilized an adapted version of ASHA's competency standards for clinical preparation and required staff to read Logemann's (1983) Evaluation and Treâtment of Swallowing Disorders. They concluded that the training provided through this program "increases the level of trust between the occupational and speech therapists due to consistent treatment approaches" (p. 371).

In addition to the development of competency standards for OTs and SLPS in their dysphagia program, Mody and Nagai (1990) also described a clinical framework developed by which patients with dysphagia are allocated to either occupational therapy or speech-language pathology. They stated that the primary division occurs with the presence or absence of communication disorders. This division involved SLP providing the primary dysphagia intervention if the patient presents with dysphagia and a concomitant communication disorder and OT providing the primary dysphagia intervention if 
the patient does not present with a communication disorder. They also reported that "these allocation guidelines are modified depending on the number of therapists available, the patient census, or both" (p. 371).

The second article on interdisciplinary activity between OTs and SLPS was found in the Journal of Allied Health (Edwards \& Hanley, 1989). A national mail survey was conducted to OTs and SLPs to determine whether "1) OTs and SLPs perceive interdisciplinary activity in similar ways, 2) OTs and SLPs engage in interdisciplinary consultations and treatment, 3) specific barriers interfere with such activity, 4) limiting factors are similar or different for OTs and SLPs, and 5) a specific set of interdisciplinary activities is pursued" (p. 377). Of the randomly selected sample, 344 of 1,250 OTs and 262 of 1,130 SLPS returned the questionnaires. Results indicated that in the medical setting, OTs and SLPs had frequent informal contacts but interdisciplinary activity was not typical of formal job descriptions. Exchange of diagnostic information was reported by $84 \%$ of OTs and $91 \%$ of SLPS to be the most common activity while both disciplines identified cooperative planning (66.6\%) and team treatment (33.3\%) as typical of their interactions. The survey also found that almost $50 \%$ of the respondents felt that "interactions were self-motivated and that the amount of interdisciplinary activity was satisfactory" (p. 375).

As acknowledged by these researchers, this study attempted to gather general information about interdisciplinary activity and identify general issues that may limit or encourage such interactions. They recommended a follow-up survey which would be more specific in addressing issues identified in this study, such as the qualitative changes needed to improve interdisciplinary 
activity and philosophical differences that undermine interdisciplinary management of health problems.

\section{Summary}

The past decade has shown an increasing base of research and literature on dysphagia in adult populations from both the occupational therapy and speech-language pathology professions. As well, many varied medical and allieu heaititi professionals have documented the value of interdisciplinary team interactions and approaches toward the management of dysphagic adults. Although interdisciplinary teamwork in medical settings is now being seen as a trend, most of the literature published has been descriptive in nature. Only one article was found which tested the efficacy of an interdisciplinary management program for neurologically impaired adults with dysphagia (Martens, Cameron, \& Simonsen, 1990). In addition, only two studies were found which specifically addressed the interdisciplinary activities between OTs and SLPS in the management of adults with dysphagia (Edwards \& Hanley, 1989; Mody \& Nagai, 1990). Both studies recommended further collaborative research in the area of dysphagia and interdisciplinary activities and relations between the professions of occupational therapy and speech-language pathology. 


\section{CHAPTER 3}

\section{DESIGN AND METHODOLOGY \\ Design of the Study}

This study employed a descriptive research design using survey methodology to examine the interdisciplinary activities and roles of occupational therapists and speech-language pathologists in the evaluation and treatment of adult patients with dysphagia and to identify issues and questions related to the overlapping of roles between these disciplines.

\section{Research Questions}

1) What are the demographics of the occupational therapists and speechlanguage pathologists surveyed?

2) What are the educational levels and backgrounds of the occupational therapists and speech-language pathologists surveyed?

3) Do C.A.R.F. accredited and/or N.A.R.F. membered California rehabilitation facilities utilize an interdisciplinary team approach to dysphagia intervention?

4) How do these facilities delineate the roles of the occupational therapists and speech-language pathologists in the evaluation and intervention of dysphagia?

5) Is there a perception of role conflict or role consonance among the occupational therapists and speech-language pathologists surveyed?

6) Is an interdisciplinary approach to dysphagia perceived to be of value for intervention? 


\section{Population and Sample}

The population for this study included occupational therapists and speech-language pathologists who work with adult populations in California rehabilitation facilities accredited by the Commission on Accreditation of Rehabilitation Facilities (C.A.R.F.) and/or members of the National Association of Rehabilitation Facilities (N.A.R.F.). A purposive, nonprobability sampling method was used to ensure a large sample size. The names and addresses of 78 California rehabilitation facilities were obtained via a mail order list from the C.A.R.F. and N.A.R.F. organizations. A total of 156 questionnaires were sent out, two to each facility.

Rehabilitation facilities were chosen as the sites to survey occupational therapists and speech-language pathologists because these settings require employment of both disciplines for accreditation, thus ensuring their presence. Further, they standardly admit patients with neurological disorders which can include swallowing dysfunction. The study was limited to the state of California due to time and budget constraints.

\section{Description of the Data Gathering Instrument}

Due to the large sample selection, a self-administered, mailed questionnaire was selected as the most appropriate data gathering instrument (Appendix A). The questionnaire format consisted of closed ended and open ended questions utilizing a combination of multiple choice, rank scaled, and fillin response questions. The open-ended and rank-scaled questions were included to specify demographic information, to provide more detailed and specific information regarding departmental issues, and to express subjective perceptions of the value of interdisciplinary relations. 
The questionnaire format began with a box to indicate the respondents' discipline and eight demographic questions addressing the respondents' place of practice, work status, age, years of clinical practice, years at current job, number of OTs and SLPs at setting, highest level of education, and name and state of college of OT or SLP education. The next six questions addressed educational and clinical information specific to the area of dysphagia.

Questions fifteen through eighteen explored issues of role conflict or harmony in the management of dysphagic patients. The remaining eight questions were specific to respondents who practiced an interdisciplinary team approach and included information on the development of the team approach, specific role delineations, discipline specific areas of expertise, specific documentation practices and reimbursement issues, and lastly, perceptions of value attributed to interdisciplinary relations.

\section{Procedure}

Prior to mailing the questionnaires to the 156 subjects, a pilot survey was administered to five occupational therapists and three speech-language pathologists in the Rehabilitation Department of Mount Zion/University of California, San Francisco Medical Centers, San Francisco, California. The therapists were asked to critically assess the instrument for clarity, ambiguity, relevance, and format. The questionnaire was then revised to incorporate the therapists' feedback and suggestions. This pilot sample was then omitted from the final sample selected for this research study.

Following the revisions, two questionnaires and consent letters (Appendix B) were mailed to 78 N.A.R.F. membered and/or C.A.R.F. accredited California rehabilitation facilities on August 13, 1993. An introductory letter (Appendix C) 
was also included stating the purpose of the study and describing the dissemination process to the prospective OT and SLP departments. The dissemination process involved the OT and SLP department heads obtaining a volunteer from each of their prospective departments to complete the enclosed questionnaires. Initially, four weeks were allowed for the data collection process with a request for the respondents to complete the questionnaires by September 15, 1993. A follow-up postcard reminder (Appendix D) was sent to the nonrespondents three weeks after the initial mailing and the collection process was extended through October 15, 1993.

\section{Statistical Technique}

Descriptive statistics utilizing measurements of central tendency and variability were used to describe the data. The independent variables studied included the specific profession of the respondents, i.e. occupational therapy or speech-language pathology, the educational and clinical backgrounds of each respondent, whether or not the respondents work together as an interdisciplinary dysphagia team, the specific role delineation of each discipline within the team, the perceptions of role conflict or role consonance of each discipline around the area of dysphagia management, and the perceived value the respondents attribute to an interdisciplinary dysphagia team approach. 


\section{CHAPTER 4 \\ DATA PRESENTATION AND RESULTS \\ Questionnaire Returns}

Of the 156 questionnaires mailed to 78 N.A.R.F. membered and/or C.A.R.F. accredited facilities, a total of $82(53 \%)$ were returned prior to the October 15 , 1993 deadline date. Of the 82 surveys returned, 19 respondents actually worked at acute hospitals or skilled nursing facilities which were N.A.R.F. members due to being "rehabilitation departments." All of the 45 facilities listed by C.A.R.F. were inpatient, acute rehabilitation facilities. The original list of N.A.R.F. facilities was reassessed to single out acute rehabilitation facilities. Of this revised list, 15 were actual acute rehabilitation facilities, which combined with the 45 C.A.R.F. accredited facilities made a total of 60 acute rehabilitation facilities surveyed. Hence, of the 120 questionnaires sent to the 60 rehabilitation facilities, 63 were returned, representing 49 facilities, a response rate of $53 \%$.

It should be noted that a considerable number of respondents did not answer some of the questions on the questionnaire, thus the representative sample in numbers varies from one data set to another. In addition, some of the following data presented is representative of the total OT and SLP respondents $(\underline{N}=63)$, while other data represent the facilities surveyed $(\underline{N}=49)$.

\section{1) What are the demographics of the occupational therapists and speech-language pathologists surveyed?}

The questionnaire respondents $(\underline{N}=63)$ were asked to provide information regarding the following seven characteristics: 1) work status (i.e. full or part time), 2) age, 3) years of clinical practice, 4) years at current setting, 5) number 
of OTs and SLPs at current setting, 6) highest level of education, and 7) location of OT or SLP college education.

Work Status:

Of the 34 OTs who responded, $100 \%$ reported their work status as full-time. Of the 28 SLPs who responded, $93 \%$ reported their work status as full-time, while $7 \%$ reported working part-time.

Age:

The reported ages of the OT and SLP participants were grouped into the following five categories: (1) under 25 , (2) 25-34, (3) 35-44, (4) 45-54, and (5) over 54. Table 1 presents the grouped responses of both the 32 OTs and 27 SLPs who responded to this question. The majority of respondents ranged from $25-34$ years of age, with $56 \%$ of both OTs and SLPs in this range. While the next highest response for OTs was in the $35-44$ years of age range (31\%), SLPS' next highest response was in the $45-54$ years of age range (26\%).

Years of Clinical Practice:

As indicated in Table 2, the average number of years of clinical practice for both OT and SLP was 10 , with $85 \%$ of the OT participants and $80 \%$ of the SLP participants reporting in the 1 to 16 year range.

\section{Years at Current Setting:}

The majority of OT respondents (62\%) reported 1 to 5 years of employment at his/her current setting while only 1 respondent reported being at their current job for over 20 years. The majority of SLP respondents (55\%) reported 1 to 5 years of employment at his/her current job, $24 \%$ reported 5 to 9 years and only 1 respondent reported being at their current setting for over 17 years. 


\section{Table 1}

Age of Occupational Therapy and Speech-Language Pathology Respondents

\begin{tabular}{lcc}
\hline \multicolumn{3}{c}{ Age of OTs } \\
\hline Age Range & Count & Percentage \\
under 25 & 2 & $6.2 \%$ \\
$25-34$ & 18 & $56.2 \%$ \\
$35-44$ & 10 & $31.2 \%$ \\
$45-54$ & 1 & $3.1 \%$ \\
over 54 & 1 & $3.1 \%$ \\
\hline & & Age of SLPs \\
\hline Age Range & Count & Percentage \\
under 25 & 1 & $3.7 \%$ \\
$25-34$ & 15 & $55.6 \%$ \\
$35-44$ & 4 & $14.8 \%$ \\
$45-54$ & 7 & $26.0 \%$ \\
over 54 & 0 & $0.0 \%$ \\
\hline
\end{tabular}




\section{Table 2}

Reported Years of Practice in Occupational Therapy and Speech-Language

Pathology

\section{Years of OT Practice}

\begin{tabular}{|c|c|c|}
\hline Range of Years & Count & Percentage \\
\hline $1-6$ & 10 & $29.4 \%$ \\
\hline $6-11$ & 10 & $29.4 \%$ \\
\hline $11-16$ & 9 & $26.5 \%$ \\
\hline $16-21$ & 3 & $8.8 \%$ \\
\hline $21-26$ & 1 & $2.9 \%$ \\
\hline $26-31$ & 0 & $0.0 \%$ \\
\hline $31-36$ & 1 & $2.9 \%$ \\
\hline \multicolumn{3}{|c|}{ Years of SLP Practice } \\
\hline Range of Years & Count & Percentage \\
\hline $1-6$ & 9 & $31.0 \%$ \\
\hline $6-11$ & 8 & $27.6 \%$ \\
\hline $11-16$ & 6 & $20.7 \%$ \\
\hline $16-21$ & 2 & $6.9 \%$ \\
\hline $21-26$ & 4 & $13.8 \%$ \\
\hline
\end{tabular}




\section{Number of OTS and SLPS at Current Setting:}

The average number of OTs reported working at their current settings was 10, whereas the average number of SLPs reported working at their current settings was 6. As the histograms indicate in Figures 1 and 2 , one OT respondent reported 40 OTs and one SLP respondent reported 29 SLPs working at their current settings.

\section{2) What are the educational levels and backgrounds of the occupational therapists and speech-language pathologists surveyed?}

Highest Level of Education:

As indicated by Figures 3 and 4, the highest level of education achieved by the respondents was examined on three levels. These levels included a baccalaureate degree (B.A./B.S.), master's degree (M.A.M.S.), and doctorate (Ph.D.). Eighty-two percent of the OT respondents reported acquiring a B.A./B.S., $18 \%$ reported acquiring a M.A.M.S. and none reported acquiring a Ph.D. as their highest educational degree. In sharp contrast, none of the SLP respondents reported acquiring less than a M.A.M.S., 97\% reported acquiring a M.A.M.S., and 3\% reported acquiring a Ph.D. as their highest educational degree.

\section{Location of OT or SLP college:}

Of the total 63 OT and SLP respondents, 35 (56\%) reported attending a California college for their OT or SLP professional education. The next most common location of OT or SLP college education was in Washington state with 9.5\% represented. As shown in Table 3, 17 states and 2 European countries in 
Figure 1

\section{Reported Number of Occupational Therapists at Rehabilitation Facilities}

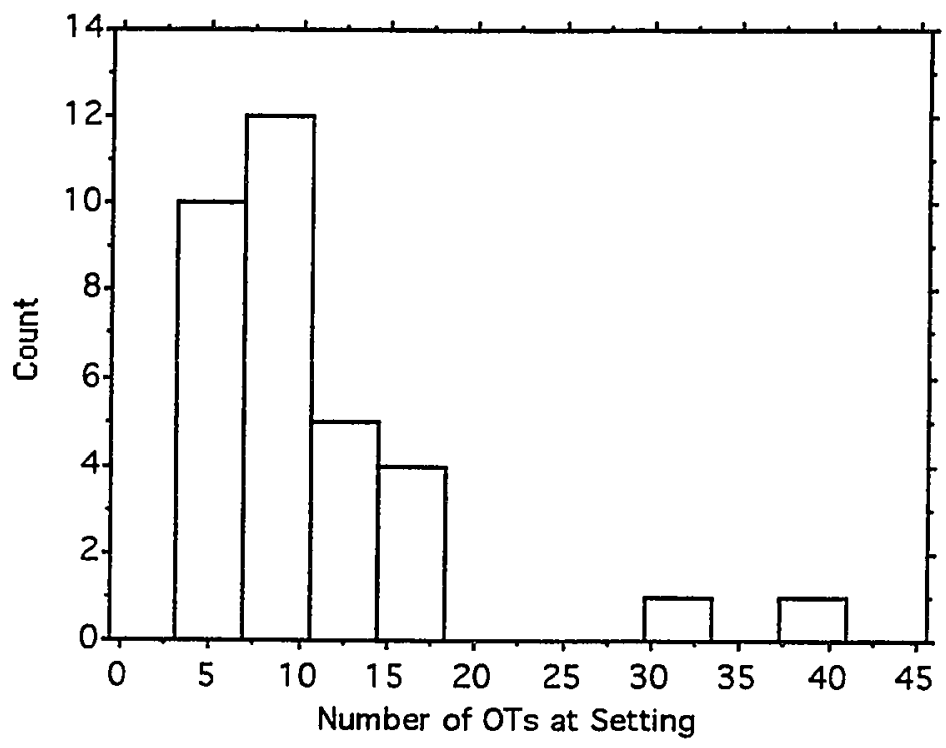


Figure 2

Reported Number of Speech-Language Pathologists at Rehabilitation Facilities

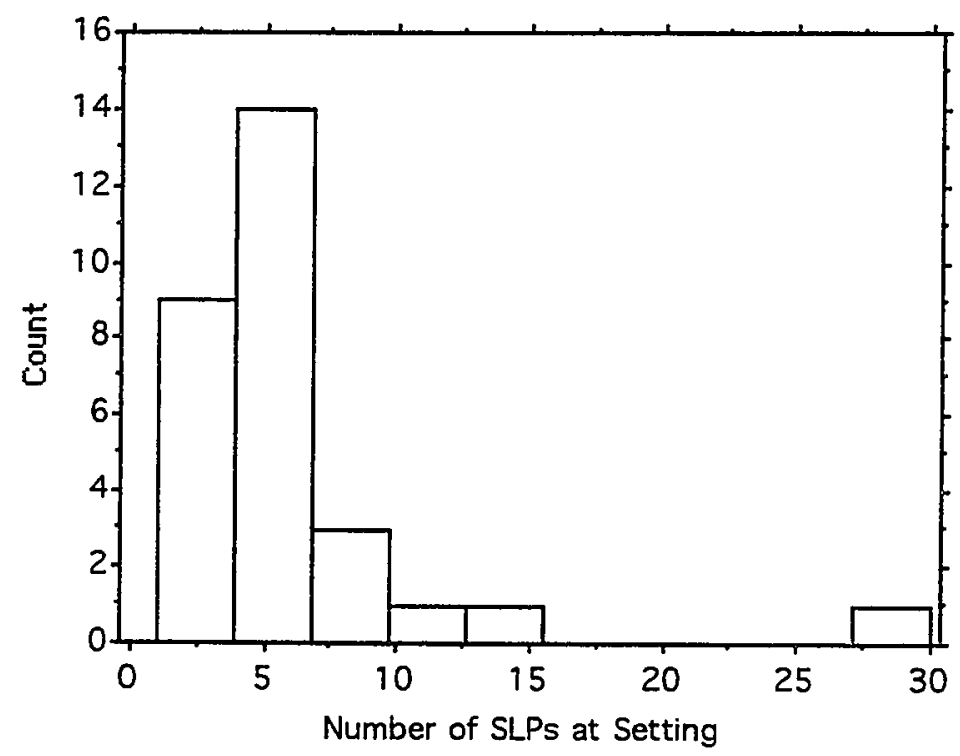


Figure 3

Highest Level of Education of Occupational Therapy Respondents

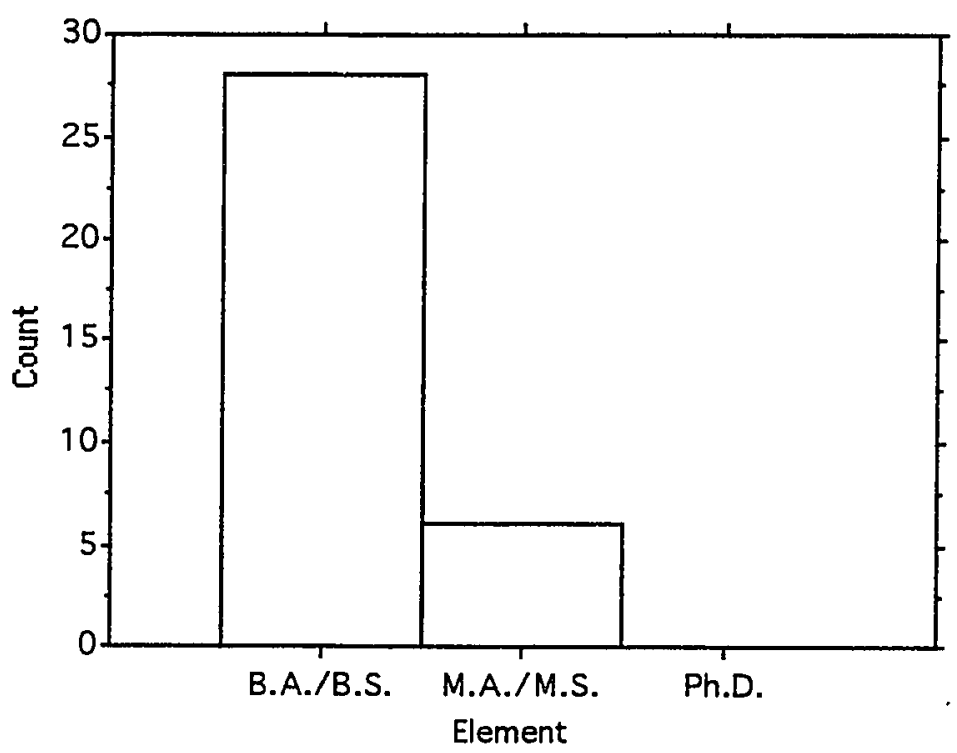


Figure 4

Highest Level of Education of Speech-Language Pathology Respondents

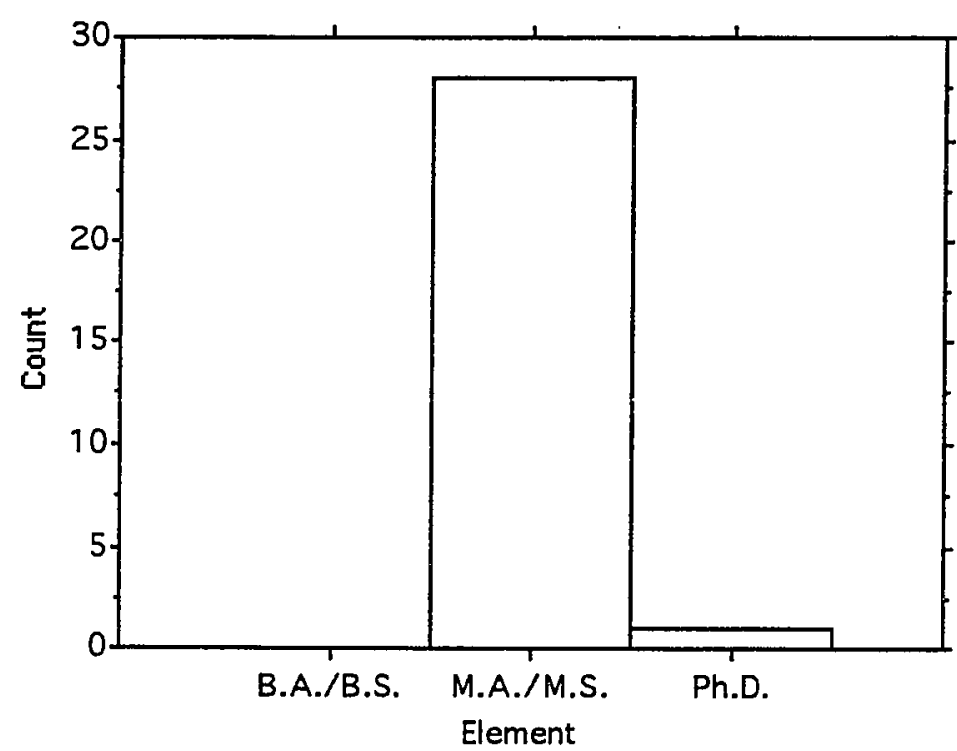


Table 3

Combined Locations of College Education in Occupational Therapy and Speech-Language Pathology

\begin{tabular}{lll}
\hline Location & Count & Percentage \\
\hline California & 35 & $55.6 \%$ \\
Washington & 6 & $9.5 \%$ \\
Massachusetts & 2 & $3.2 \%$ \\
Minnesota & 2 & $3.2 \%$ \\
Missouri & 2 & $3.2 \%$ \\
Colorado & 2 & $3.2 \%$ \\
New York & 2 & $3.2 \%$ \\
Alabama & 1 & $1.6 \%$ \\
Arizona & 1 & $1.6 \%$ \\
Florida & 1 & $1.6 \%$ \\
Illinois & 1 & $1.6 \%$ \\
Michigan & 1 & $1.6 \%$ \\
New Mexico & 1 & $1.6 \%$ \\
Oklahoma & 1 & $1.6 \%$ \\
Pennsylvania & 1 & $1.6 \%$ \\
Texas & 1 & $1.6 \%$ \\
Virginia & 1 & $1.6 \%$ \\
Denmark & 1 & $1.6 \%$ \\
Ireland & $1.6 \%$ \\
\hline
\end{tabular}


total were represented as the locations where the OTs and SLPs received their college education.

Educational Backgrounds and Professional Skills in Dysphagia Management

Of the 32 OT respondents, $84 \%$ reported having the professional skills to evaluate and treat patients with dysphagia, while of the 29 SLP respondents, $100 \%$ reported being skilled in dysphagia intervention. As shown in Table 4, the participants were asked to indicate which of the following places they developed skills in dysphagia management: a) college, b) internships, c) continued education courses, d) past place/s of employment, and/or e) current place of employment. Of the 33 OT respondents, $48 \%$ identified college, $30 \%$ internships, $67 \%$ continued education courses, $55 \%$ past place/s of employment, and $73 \%$ current place of employment as places of their dysphagia management skill development. Of the 29 SLP respondents, $34 \%$ identified college, $59 \%$ internships, $100 \%$ continued education courses, $55 \%$ past place/s of employment, and $90 \%$ current place of employment as place(s) where they developed their skills in dysphagia intervention.

The participants were then asked to approximate how many hours of training in the area of dysphagia intervention they received in college (specifically excluding internships). As indicated in Figure 5, of the 29 OT respondents, 3\% reported zero hours, $69 \%$ reported 1 to 5 hours, $17 \%$ reported 5 to 10 hours, $7 \%$ reported 10 to 20 hours, none reported 40 to 60 hours, and $3 \%$ reported 80 or more hours of training in the area of dysphagia intervention. As shown in Figure 6, of the 29 SLP respondents, $48 \%$ reported zero hours, $24 \%$ reported 1 to 5 hours, $7 \%$ reported 5 to 10 hours, $10 \%$ reported 10 to 20 
Table 4

Places of Skill Development in Dysphagia Management

\begin{tabular}{llll}
\hline & $\begin{array}{l}\text { SLP(\%) } \\
n=29\end{array}$ & $\begin{array}{l}\text { OT(\%) } \\
n=33\end{array}$ & $\begin{array}{l}\text { Total(\%) } \\
n=62\end{array}$ \\
\hline a. Col!ege & $10(34 \%)$ & $16(48 \%)$ & $26(42 \%)$ \\
b. Internships & $17(59 \%)$ & $10(30 \%)$ & $27(44 \%)$ \\
c. Continued & $29(100 \%)$ & $22(67 \%)$ & $51 \quad(82 \%)$ \\
education & $16(55 \%)$ & $18(55 \%)$ & $34(55 \%)$ \\
d. Past employment & $26(90 \%)$ & $24(73 \%)$ & $50(80 \%)$ \\
e. Current & & & \\
\hline
\end{tabular}


Figure 5

Occupational Therapy College Course Hours in Dysphagia

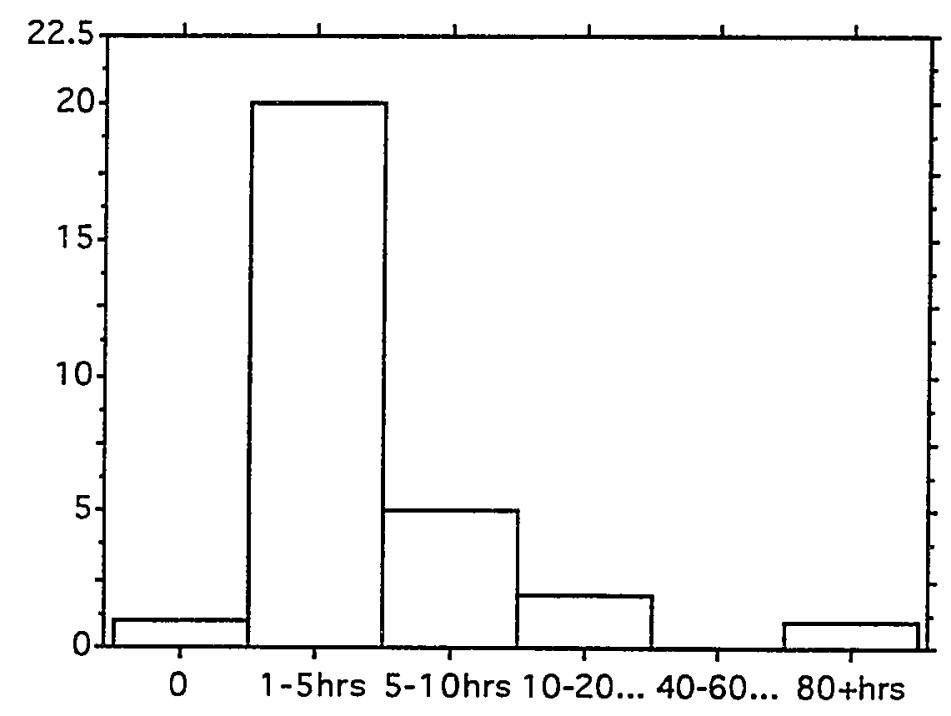


Figure 6

Speech-Language Pathology College Course Hours in Dysphagia

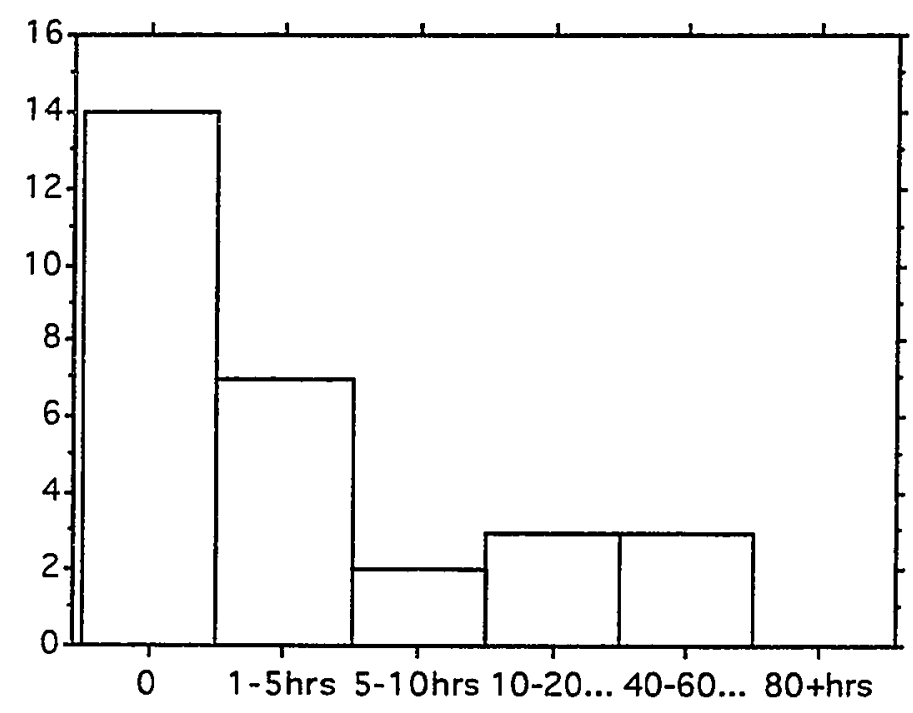


hours, $10 \%$ reporied 40 to 60 hours, and none reported 80 or more hours of training in the area of dysphagia intervention.

\section{3) Do C.A.R.F. accredited and/or N.A.R.F. membered California rehabilitation facilities utilize an interdisciplinary approach to dysphagia intervention?}

As displayed in Figure 7, of the 49 facilities who responded to this survey, $19(39 \%)$ reported OT and SLP interdisciplinary team as responsible for the

primary evaluation and treatment of the patients with dysphagia, while $27(55 \%)$ reported SLP, $2(4 \%)$ reported OT, and $1(2 \%)$ reported physical therapy as the primary discipline responsible for dysphagia case management.

Participants were then asked to identify factors which contributed to the development of an OTISLP interdisciplinary team approach to dysphagia management. Of the 48 respondents, $58 \%$ reported specific dysphagia intervention skills of the OTs and SLPs, $40 \%$ reported staff recommendations, $25 \%$ reported departmental policy, $10 \%$ reported research or studies advocating the benefits of a team approach, and $10 \%$ reported "other" as contributing factors toward the development of an OT/SLP team approach to dysphagia cases. Some of the "other" responses included the following statements: "to avoid turf wars," "new staff with a specific interest," "concern for well-being/benefit to patient," and "focus has been on development of a dysphagia program rather than OT or ST dysphagia program."

The participants were then asked if their facility does not have an OT/SLP interdisciplinary team approach toward dysphagia, would they like to see one developed. As shown in Table 5, of the 35 respondents who do not follow a team approach with dysphagia cases, $28 \%$ of OTs and $35 \%$ of SLPs would like 
Figure 7

Discipline(s) Responsible for Primary Evaluation and Treatment of Patients with Dysphagia

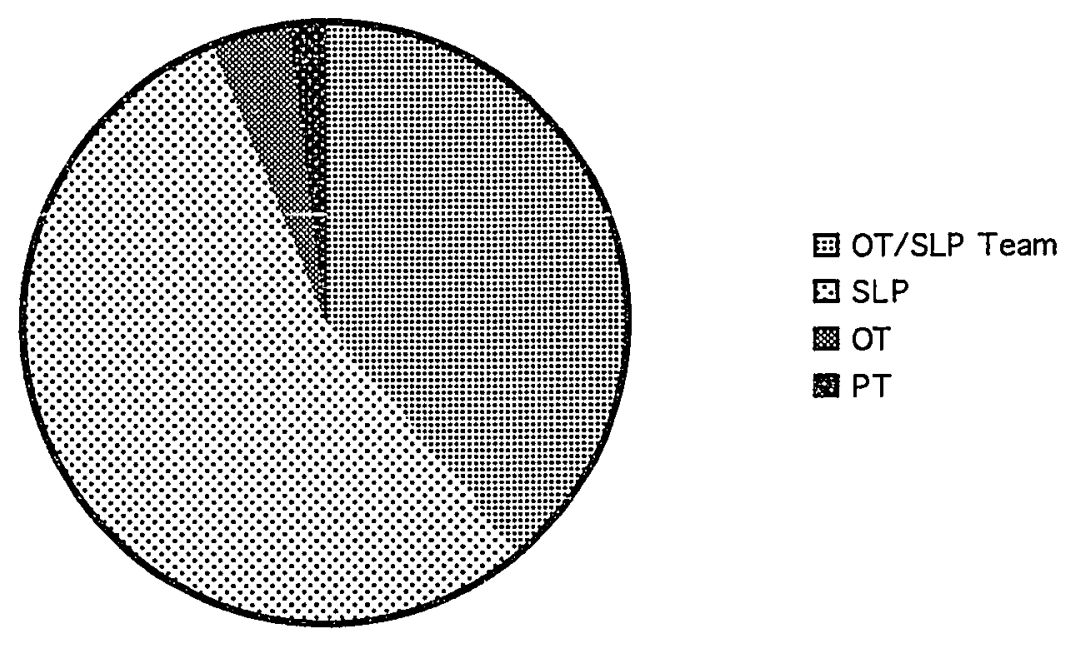




\section{Table 5}

Do Respondents want to see a Team Developed?

\begin{tabular}{llllllll}
\hline & \multicolumn{2}{c}{ Yes } & No & & No Response \\
\hline OT $\quad(\underline{n}=18)$ & 5 & $(28 \%)$ & 4 & $(22 \%)$ & 9 & $(50 \%)$ \\
SLP $(\underline{n}=17)$ & 6 & $(35 \%)$ & 5 & $(29 \%)$ & 6 & $(35 \%)$ \\
Total $(\underline{n}=35)$ & $11 \quad(31 \%)$ & 9 & $(26 \%)$ & 15 & $(43 \%)$ \\
\hline
\end{tabular}


to see a team approach developed and $22 \%$ of OTs and $29 \%$ of SLPs would not like to see a team approach developed. The remaining $43 \%$ of participants did not respond to this question.

\section{4) How do these facilities delineate the roles of the occupational therapists and speech-language pathologists in the evaluation and intervention of dysphagia?}

The participants were asked to indicate which of the following areas of dysphagia evaluation and intervention were a part of OT's role, SLP's role, "either" (referring to OT or SLP), "jointly" (referring to OT and SLP), or "other" (referring to a discipline other than OT or SLP): a) bedside dysphagia evaluations, b) videofluoroscopies, c) feeding/meal groups, d) thermal stimulation, e) oral-facial exercises, $f$ ) self-feeding retraining, g) compensatory head techniques, h) postural positioning, i) diet upgrades, and j) family training in dysphagia intervention.

As shown in Tables 6, 7, and 8, the role delineations in dysphagia case management are displayed for the facilities that use an OTISLP interdisciplinary team approach, the facilities which do not use an OTISLP interdisciplinary team approach, and the total facility respondents. As seen in Table 6, a large number of the roles are delineated for "either" OT or SLP and "jointly" OT and SLP with the exception of self-feeding retraining which $74 \%$ reported as an OT role, postural positioning which $42 \%$ reported as an OT role, and administering videofluoroscopies which $21 \%$ reported as a SLP role.

Of the 30 facilities which reportedly do not use an OT/SLP interdisciplinary team approach in dysphagia case management, 22 responded to all items in the question regarding role delineations with the exception of thermal 
Table 6

Role Delineation in Dysphagia Case Management for the Facilities that use an Interdisciplinary Team Approach

$\underline{n}=19$

\begin{tabular}{|c|c|c|c|c|c|}
\hline & SLP(\%) & Or(\%) & Joinily(\%) & Either(\%) & Other $(\%)$ \\
\hline Bedside evaluations & $1(5 \%)$ & $0(0 \%)$ & $4(21 \%)$ & $14(74 \%)$ & $0 \quad(0 \%)$ \\
\hline Videofluoroscopies & $4(21 \%)$ & $0(0 \%)$ & $3(16 \%)$ & $12(63 \%)$ & $0(0 \%)$ \\
\hline Feeding/meal grps. & $0(0 \%)$ & $3(16 \%)$ & $7(37 \%)$ & $(42 \%)$ & $1 \quad(5 \%)$ \\
\hline $\begin{array}{l}\text { Oral-facial } \\
\text { exercises }\end{array}$ & $2(11 \%)$ & $0(0 \%)$ & $3(16 \%)$ & $14 \quad(74 \%)$ & $0(0 \%)$ \\
\hline $\begin{array}{l}\text { Self-feeding } \\
\text { retraining }\end{array}$ & $0(0 \%)$ & $14(74 \%)$ & $2(11 \%)$ & $(16 \%)$ & $0 \quad(0 \%)$ \\
\hline $\begin{array}{l}\text { Compensatory } \\
\text { head techniques }\end{array}$ & $1(5 \%)$ & $1(5 \%)$ & $3(16 \%)$ & $14(74 \%)$ & $0 \quad(0 \%)$ \\
\hline $\begin{array}{l}\text { Postural } \\
\text { positioning }\end{array}$ & $0(0 \%)$ & $8(42 \%)$ & $1(5 \%)$ & $10 \quad(53 \%)$ & $0 \quad(0 \%)$ \\
\hline Diet upgrades & $1(5 \%)$ & $0(0 \%)$ & $5(26 \%)$ & $13(68 \%)$ & $0 \quad(0 \%)$ \\
\hline Family training & $1(5 \%)$ & $0(0 \%)$ & $4(21 \%)$ & $14(74 \%)$ & $0(0 \%)$ \\
\hline $\begin{array}{l}\text { Thermal } \\
\text { stimulation }\end{array}$ & $1(5 \%)$ & $0(0 \%)$ & $3(16 \%)$ & $15(79 \%)$ & $0 \quad(0 \%)$ \\
\hline
\end{tabular}


stimulation to which only 19 participants responded. As Table 7 shows, a large percentage of facilities delineated roles which are directly related to oropharyngeal swallowing assessment and treatment, such as bedside dysphagia evaluations, videofluoroscopies, and thermal stimulation, to speech-language pathology. Again, self-feeding retraining (86\%) and postural positioning (41\%) were largely designated as OT roles. Areas of overlap in roles included feeding/meal groups, oral-facial exercises, self-feeding retraining, compensatory head techniques, postural positioning, diet upgrades, family training, and thermal stimulation.

As indicated in Table 8, for the 41 total facility responses, speech-language pathology remained predominant in the delineated roles of primary dysphagia services, such as bedside evaluation (46\%) and videofluoroscopies (56\%). On the other hand, nearly half of the total respondents indicated "either" OT or SLP for the roles of oral-facial exercises, compensatory head techniques, postural positioning, diet upgrades, family training, and thermal stimulation.

\section{5) Is there a perception of role conflict or role consonance among the occupational therapists and speech-language pathologists surveyed?}

Of the 62 respondents, $11(18 \%)$ reported the existence of role conflict or territorialism in the area of dysphagia management. Of those 11 respondents, 6 were OTs and 5 were SLPs. On the other hand, 47 respondents (76\%) reported the existence of role consonance or harmony in the area of dysphagia intervention. Of those 47 respondents, 24 were OTs and 23 were SLPs. Four respondents $(6 \%)$ reported the existence of both role conflict and role harmony. Of those 4 respondents, 3 were OTs and 1 was a SLP. 


\section{Table 7}

Role Delineation in Dysphagia Case Management for the

Facilities that don't use an OT/SLP Interdisciplinary Team Approach

$\underline{\mathrm{n}}=22$

\begin{tabular}{|c|c|c|c|c|c|c|c|}
\hline & $\operatorname{SLP}(\%)$ & OT(\%) & Jointly(\%) & & $\operatorname{er}(\%)$ & \multicolumn{2}{|c|}{ Other(\%) } \\
\hline Bedside evaluations & $18(82 \%)$ & $2(9 \%)$ & $1(5 \%)$ & 1 & $(5 \%)$ & 0 & $(0 \%)$ \\
\hline Videofluoroscopies & $19(86 \%)$ & $2(9 \%)$ & $1(5 \%)$ & 0 & $(0 \%)$ & 0 & $(0 \%)$ \\
\hline Feeding/meal grps. & $1(5 \%)$ & $7 \quad(32 \%)$ & $6(27 \%)$ & 7 & $(32 \%)$ & 1 & $(5 \%)$ \\
\hline $\begin{array}{l}\text { Oral/facial } \\
\text { exercises }\end{array}$ & $13(59 \%)$ & $0(0 \%)$ & $3(14 \%)$ & 6 & $(27 \%)$ & 0 & $(0 \%)$ \\
\hline $\begin{array}{l}\text { Self-feeding } \\
\text { retraining }\end{array}$ & $0(0 \%)$ & $19(86 \%)$ & $0(0 \%)$ & 3 & $(14 \%)$ & 0 & $(0 \%)$ \\
\hline $\begin{array}{l}\text { Compensatory } \\
\text { head techniques }\end{array}$ & $9(41 \%)$ & $4(18 \%)$ & $2(9 \%)$ & 7 & $(32 \%)$ & 0 & $(0 \%)$ \\
\hline $\begin{array}{l}\text { Postural } \\
\text { positioning }\end{array}$ & $3(14 \%)$ & $9(41 \%)$ & $3(14 \%)$ & 7 & $(32 \%)$ & 0 & $(0 \%)$ \\
\hline Diet upgrades & $14(64 \%)$ & $1(5 \%)$ & $2(9 \%)$ & 5 & $(23 \%)$ & 0 & $(0 \%)$ \\
\hline Family training & $14(64 \%)$ & $1(5 \%)$ & $4(18 \%)$ & 3 & $(14 \%)$ & 0 & $(0 \%)$ \\
\hline $\begin{array}{l}\text { Thermal } \\
\text { stimulation }\end{array}$ & $16(84 \%)$ & $0(0 \%)$ & $0(0 \%)$ & 3 & $(16 \%)$ & 0 & $(0 \%)$ \\
\hline
\end{tabular}

Note. Eight of the 30 respondents who do not use a team approach did not answer this question. 


\section{Table 8}

Role Delineation in Dysphagia Case Management for all Facilities $\underline{\mathrm{n}}=\mathbf{4 9}$

\begin{tabular}{|c|c|c|c|c|c|c|c|}
\hline & SLP(\%) & OT(\%) & Jointly(\%) & Eith & $\operatorname{er}(\%)$ & \multicolumn{2}{|c|}{ Other(\%) } \\
\hline Bedside evaluations & $19(46 \%)$ & $2(15 \%)$ & $5(12 \%)$ & 15 & $(37 \%)$ & 0 & $(0 \%)$ \\
\hline Videofluoroscopies & $23(56 \%)$ & $2(5 \%)$ & $4(10 \%)$ & 12 & $(29 \%)$ & $\overline{0}$ & $(0 \%)$ \\
\hline Foeding/meal grps. & $1(2 \%)$ & $10(24 \%)$ & $13(32 \%)$ & 15 & $(37 \%)$ & 2 & $(5 \%)$ \\
\hline $\begin{array}{l}\text { Oral-facial } \\
\text { exercises }\end{array}$ & $15(37 \%)$ & $0(0 \%)$ & $6(15 \%)$ & 20 & $(49 \%)$ & 0 & $(0 \%)$ \\
\hline $\begin{array}{l}\text { Self-feeding } \\
\text { retraining }\end{array}$ & $0(0 \%)$ & $33(84 \%)$ & $2(5 \%)$ & 6 & $(15 \%)$ & 0 & $(0 \%)$ \\
\hline $\begin{array}{l}\text { Compensatory } \\
\text { head techniques }\end{array}$ & $10(24 \%)$ & $5(12 \%)$ & $5(12 \%)$ & 21 & $(51 \%)$ & 0 & $(0 \%)$ \\
\hline $\begin{array}{l}\text { Postural } \\
\text { positioning }\end{array}$ & $3(7 \%)$ & $17(41 \%)$ & $4(10 \%)$ & 17 & $(41 \%)$ & 0 & $(0 \%)$ \\
\hline Diet upgrades & $15(37 \%)$ & $1(2 \%)$ & $7(17 \%)$ & 18 & $(44 \%)$ & 0 & $(0 \%)$ \\
\hline Family training & $15(37 \%)$ & $1(2 \%)$ & $8(20 \%)$ & 17 & $(41 \%)$ & 0 & $(0 \%)$ \\
\hline $\begin{array}{l}\text { Thermal } \\
\text { stimulation }\end{array}$ & $17(45 \%)$ & $0(0 \%)$ & $3(8 \%)$ & 18 & $(47 \%)$ & 0 & $(0 \%)$ \\
\hline
\end{tabular}


As shown in Table 9, 15 respondents indicated which of the following factors they felt contributed to the presence of role conflict in the area of dysphagia management: a) philosophic differences, b) conflicting case management strategies, c) staffing issues, d) personality conflicts, e) threat of loss of professional role, $f$ ) threat of loss of current position, $g$ ) lack of knowledge/exposure to other disciplines, and $h$ ) other. Of the 9 OTs who responded to this question, $56 \%$ indicated philosophic differences; staffing issues, and threat of loss of professional role as the leading factors, while $22 \%$ reported lack of knowledge and exposure to other disciplines as a contributing factor to role conflict. Of the 6 SLPs who answered this question, $67 \%$ reported philosophic differences and conflicting case management strategies as the leading factors, while $50 \%$ reported threat of loss of professional role and lack of knowledge and exposure to other disciplines as factors contributing to role conflict.

As shown in Table 10,51 respondents indicated which of the following factors contributed to role consonance or harmony: a) acceptance that one discipline (OT or SLP) has more expertise in the area of dysphagia, $b$ ) acceptance that each discipline brings its unique skills and knowledge to the management of dysphagia patients, c) our facility has an OT/SLP team approach to dysphagia which created more constructive exposure to the other discipline, d) perception that the dysphagic patients benefit from OTISLP team approach even if the roles overlap, e) the roles of OT and SLP are well differentiated in the management of dysphagia, and f) other. 
Table 9

OT and SLP Respondents Reporting Factors Contributing to Role Conflict $\underline{n}=15$

\begin{tabular}{|c|c|c|c|}
\hline Factor & $\begin{array}{l}\text { OT }(\%) \\
(n=9)\end{array}$ & $\begin{array}{l}\operatorname{SLP}(\%) \\
(n=6)\end{array}$ & $\begin{array}{l}\text { Total }(\%) \\
(n=15)\end{array}$ \\
\hline a. Philosophic differences & $5(56 \%)$ & $4(67 \%)$ & $9(60 \%)$ \\
\hline $\begin{array}{l}\text { b. Conflicting case management } \\
\text { strategies }\end{array}$ & $1(11 \%)$ & $4(67 \%)$ & $5(33 \%)$ \\
\hline c. Staffing issues & $4(44 \%)$ & $1(17 \%)$ & $5(33 \%)$ \\
\hline d. Personality conflicts & $1(11 \%)$ & $2(33 \%)$ & $3(20 \%)$ \\
\hline $\begin{array}{l}\text { e. Threat of loss of } \\
\text { professional role }\end{array}$ & $5(56 \%)$ & $3(50 \%)$ & $8(53 \%)$ \\
\hline $\begin{array}{l}\text { f. Threat of loss of } \\
\text { current position }\end{array}$ & $0(0 \%)$ & $0(0 \%)$ & $0(0 \%)$ \\
\hline $\begin{array}{l}\text { g. Lack of knowledge/exposure } \\
\text { to other disciplines }\end{array}$ & $2(22 \%)$ & $3(50 \%)$ & $5(33 \%)$ \\
\hline h. Other & $0(0 \%)$ & $0(0 \%)$ & $0(0 \%)$ \\
\hline
\end{tabular}




\section{Table 10}

OT and SLP Respondents Reporting Factors Contributing to Role Harmony $\underline{n}=51$

Factor
SLP $(\%)$

$(\underline{n}=24)$
OT(\%)

(n)=27)
Total(\%)

$(\underline{n}=51)$ a. Acceptance that one discipline has more expertise in the area of dysphagia

b. Acceptance that each discipline brings its unique skills and knowledge to the management of dysphagic patients

c. Our facility has an OT/SLP team approach to dysphagia which creates more constructive exposure to the other discipline

d. Perception that the dysphagic patients benefit from OT/SLP team approach even if the roles overlap

e. The roles of OT and SLP are well differentiated in the management of dysphagia

f. Other
$12(50 \%) \quad 11$ (41\%) $23 \quad(45 \%)$

$14(58 \%) \quad 13 \quad(48 \%) \quad 27 \quad(53 \%)$

$11(46 \%) \quad 8 \quad(30 \%) \quad 19 \quad(37 \%)$

$11(46 \%) \quad 8 \quad(30 \%) \quad 19 \quad(37 \%)$

$7(29 \%) \quad 5(19 \%) \quad 12(24 \%)$

$3(13 \%) \quad 0(0 \%) \quad 3(6 \%)$ 
Of the total OT and SLP respondents identifying contributing factors to role harmony, 53\% reported acceptance that each discipline brings its unique skills to dysphagic patients, $39 \%$ reported that their facility has an OT/SLP team approach to dysphagia creating exposure to the other discipline, and $37 \%$ reported the perception that patients benefit from the team approach even if roles overlap. On the other hand, $47 \%$ of the total respondents reported acceptance that one discipline has more expertise in dysphagia management and $24 \%$ reported that well differentiated OT/SLP roles in the area of dysphagia contribute to role consonance.

\section{6) Is an interdisciplinary approach to dysphagia perceived to be of value for intervention?}

Of the 63 questionnaires received, 50 participants $(79 \%)$ responded to this question, indicating the level of value attributed to interdisciplinary relations with OT or SLP in the area of dysphagia intervention. As displayed in Table 11, of the 50 respondents, $60 \%$ reported OT/SLP interdisciplinary relations in dysphagia case management to be very valuable, $28 \%$ reported relations to be moderately valuable, $10 \%$ reported relations to be minimally valuable, and $2 \%$ reported relations to be of no value.

The responses to the open-ended question regarding reasons attributed to the level of value found in OT/SLP interdisciplinary relations were grouped into 7 response categories for "very valuable" and "moderately valuable" and 4 response categories for "minimally valuable" and "no value."

As shown in Table 12, 24 OTs and 18 SLPs listed the following reasons for very valuable or moderately valuable interdisciplinary relations with SLP or OT in the area of dysphagia management: a) $83 \%$ of OTs and $94 \%$ of SLPS 


\section{Table 11}

Level of Value Attributed to OT/SLP Interdisciplinary Relations in the Area of Dysphagia

$\underline{n}=50$

\begin{tabular}{lcl}
\hline Value & Number & Percentage \\
\hline Very & 30 & $60 \%$ \\
Moderate & 14 & $28 \%$ \\
Minimal & 5 & $10 \%$ \\
None & 1 & $2 \%$ \\
\hline
\end{tabular}


Table 12

Reasons Attributed to Very Valuable or Moderately Valuable Interdisciplinary OT/SLP Relations in Dysphagia Management $\underline{\mathrm{n}}=42$ (24 OTs and 18 SLPs)

\begin{tabular}{lll}
\hline \multicolumn{1}{c}{ Reasons } & \multicolumn{2}{c}{ Percentages } \\
& OT & SLP \\
\hline 1) "Improved quality of care to patient" & $83 \%$ & $94 \%$ \\
2) "Increased team support and communication" & $17 \%$ & $55 \%$ \\
3) "Provides increased knowledge of other & $17 \%$ & $28 \%$ \\
$\quad$ profession's expertise" & & \\
4) "Combined expertise of two professions & $21 \%$ & $22 \%$ \\
5) "Assists with staffing issues" & & \\
6) "Frees up OT and SLP to work on other areas" & $4 \%$ & $17 \%$ \\
7) "Helps with difficult cases" & $4 \%$ & $0 \%$ \\
\hline
\end{tabular}


reported "improved quality of care to patient" which included increased progress, increased treatment efficiency, increased continuity of care, treating patient as whole person, and reducing aspiration risk by increased therapist contact time, b) $17 \%$ of OTs and $55 \%$ of SLPs reported "increased team support and communication," c) $17 \%$ of OTs and $28 \%$ of SLPs reported "provides increased knowledge of other profession's expertise," d) $21 \%$ of OTs and $22 \%$ of SLPs reported "combined expertise of two professions benefit the patient," e) $4 \%$ of OTs and $17 \%$ of SLPs reported "assists with staffing issues," f) $4 \%$ of OTs reported "frees up OT and SLP to work on other areas," and g) $5 \%$ of SLPS reported "helps with difficult cases."

As displayed in Table 13,5 OTs and 1 SLP listed the following reasons for minimal value or no value attributed to interdisciplinary relations with OT or SLP in dysphagia intervention: a) OT = 3 for "no team approach," b) OT $=1$ for "OT is only allowed to do self-feeding," c) OT $=1$ for "OTs are aware of SLP's intervention with dysphagia patients and respect their expertise," and d) SLP = 1 for "OT does not have the educational background for dysphagia management."

\section{Other Relevant Data}

In addition to the data gathered to answer the specific research questions, further questions were asked to gather data relevant to the management of dysphagia. The participants were asked to identify specific factors which contributed to the development of an interdisciplinary team approach to dysphagia management at their facilities. Of the 63 respondents, 48 OTs and SLPS reported the following contributing factors: a) departmental policy (27\%), 
Table 13

Reasons Attributed to Minimal Value or No Value Placed on Interdisciplinary OT/SLP Relations in Dysphagia Management

$\underline{n}=6$ (5 OTs and 1 SLP)

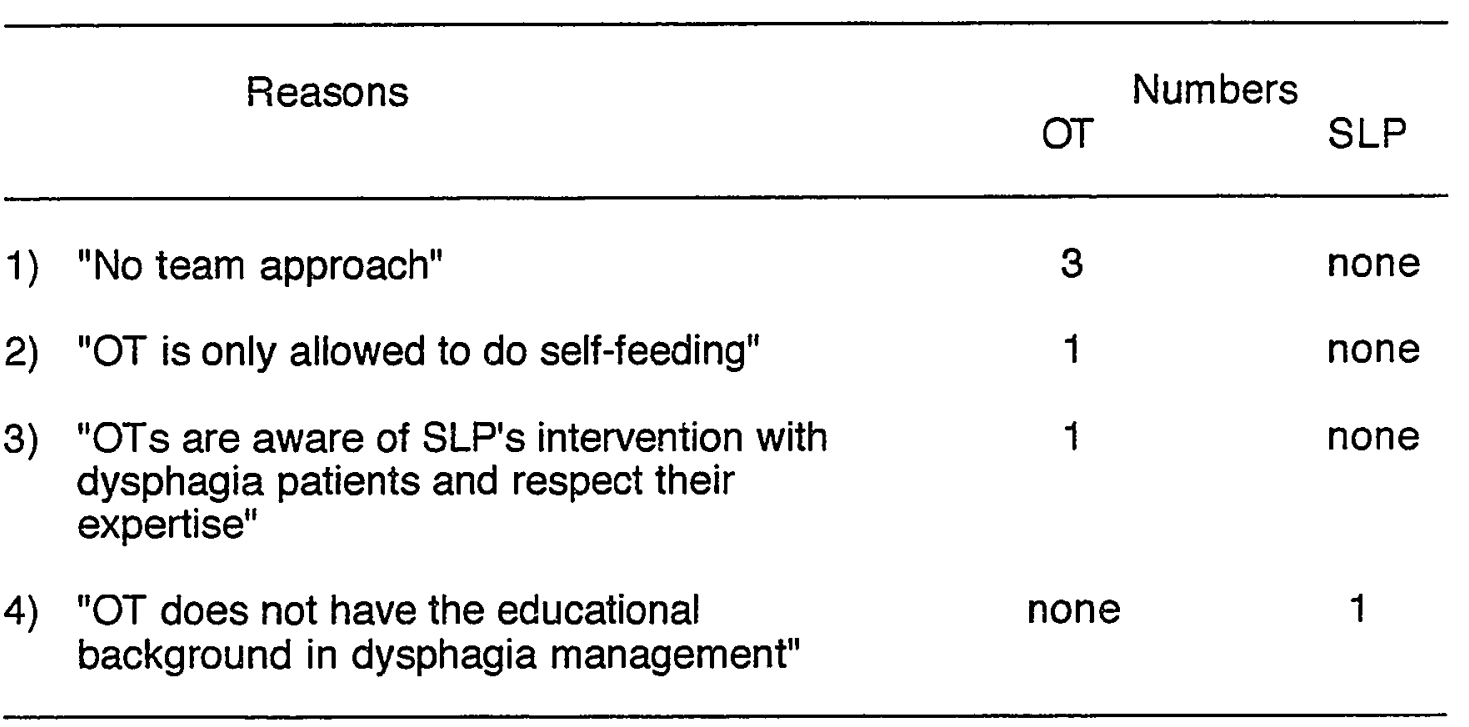


b) specific skills of each discipline $(58 \%)$, c) research studies (10\%), d) staff recommendations $(42 \%)$, and e) other (15\%).

The participants were also asked to identify their discipline's areas of unique expertise which they felt contributed to their role in the interdisciplinary team approach to the dysphagic patient. As indicated in Table 14, of the 32 OT and 22 SLP respondents, $38 \%$ of OTs and $100 \%$ of SLPs reported knowledge of oral, pharyngeal, and esophageal structures and functions, $47 \%$ of OTs and $100 \%$ of SLPs cited knowledge of normal and disordered swallowing and its evaluation and treatment, $16 \%$ of OTs and $95 \%$ of SLPs reported knowledge of normal anatomy and physiology of speech structures and processes, $72 \%$ of OTs and $73 \%$ of SLPs reported knowledge of overall sensory-motor control and function, $91 \%$ of OTs and $64 \%$ of SLPs reported knowledge of functional positioning techniques, $100 \%$ of OTs and $85 \%$ of SLPs reported knowledge of cognitive and visual-perceptual skills/deficits, $75 \%$ of OTs and $68 \%$ of SLPS reported knowledge of psychosocial components, and lastly, $100 \%$ of OTs and $23 \%$ of SLPs reported knowledge of seli-feeding skill components as unique areas of expertise which enhances the team approach to the dysphagic patient.

The participants were then asked if their departments had developed specific documentation practices to differentiate OT/SLP roles in dysphagia management for reimbursement purposes. Of the 35 facilities which responded to this question, 14 (40\%) circled "yes" and 21 (60\%) circled "no" to the existence of specific documentation practices for reimbursement of dysphagia management. Thirteen facilities listed the following documentation practices to differentiate OT/SLP roles in dysphagia management: 7 reported self-feeding therapy documented for OT role and swallowing therapy documented for SLP 
Table 14

OT and SLP Perceived Areas of Unique Expertise Contributing to Dysphagia Intervention

$\begin{array}{lll}\text { Area of Expertise } & \underset{(\underline{n}=32)}{\text { OT }(\%)} & \underset{(\underline{n}=22)}{\operatorname{SLP}}(\%)\end{array}$

a. Knowledge of oral, pharyngeal, and esophageal structures and function

b. Knowledge of normal and disordered swallowing and its evaluation and treatment

c. Knowledge of normal anatomy and physiology of speech structures and processes

d. Knowledge of overall sensorymotor control and function

e. Knowledge of functional positioning techniques

f. Knowledge of cognitive and visual perceptual skills/deficits

$12(38 \%) 22$ (100\%)

$15(47 \%) \quad 22 \quad(100 \%)$

$5(16 \%) \quad 21 \quad(95 \%)$

g. Knowledge of psychosocial components

$23(72 \%) \quad 16 \quad(73 \%)$

$29(91 \%) \quad 14 \quad(64 \%)$

$32(100 \%) \quad 19 \quad(86 \%)$

h. Knowledge of self-feeding skill components

$24(75 \%) \quad 15 \quad(68 \%)$

$32(100 \%) \quad 3(14 \%)$ 
role, 2 reported self-feeding, positioning, behavioral, and cognitive-perceptual intervention documented for OT role and swallowing intervention documented for SLP role, 1 reported that both departments relate their documentation to specific discipline goals, and lastly, 3 reported that only one discipline (either

OT or SLP) follows a dysphagic patient as the primary swallowing therapist and is responsible for primary dysphagia documentation.

In addition, the participants were questioned whether or not reimbursement issues had arisen regarding duplicable services between OT and SLP in the area of dysphagia evaluation and treatment. Of the 37 facilities who answered this question, 2 (5\%) circled "yes" and 35 (95\%) circled "no" to the existence of reimbursement issues. The 2 facilities that experienced reimbursement issues both reported billing conflicts when the two disciplines (OT/SLP) participated in the videofluoroscopic swallow studies for one patient with specific duplications noted in documentation practices.

Finally, a chi-square test was performed to assess whether there was a significant relationship among the facilities which did or did not utilize an OT/SLP team approach to dysphagia management and the existence of perceived territorial or harmonious factors. No significant relationship was found $(\mathrm{p}=.91)$. A chi-square test was also performed to determine whether a significant relationship existed among the facilities which did or did not utilize an OTISLP dysphagia team approach and the perception of a higher level of value placed on OT/SLP interdisciplinary relations. No significant relationship was found $(\underline{p}=.18)$. 


\section{Chapter 5 \\ SUMMARY, \\ PROFESSIONAL IMPLICATIONS, \\ AND CONCLUSIONS}

\section{Summary}

In the past 20 years the body of multidisciplinary dysphagia literature has grown from several descriptive studies or case reports of dysphagia team management approaches to beginning efficacy studies supporting the benefits of multidisciplinary dysphagia management programs (Martens, Cameron, \& Simonsen, 1990). Over the past 50 years, both occupational therapists and speech-language pathologists have been involved in rehabilitative swallowing and feeding programs (Mody \& Nagai, 1990). Although descriptions of their interdisciplinary team roles in dysphagia management for adult populations have emerged from a diverse body of allied health literature, these descriptions have varied from one article to another (Bach et al., 1989; Emick-Herring \& Wood, 1990; Hynak-Hankinson et al., 1984). The need to clarify and define OT and SLP roles in dysphagia management has become strongly evident.

The purpose of this study was to explore the interdisciplinary activities and relations between occupational therapists and speech-language pathologists in the evaluation and treatment of adults with dysphagia. In order to accomplish this, a descriptive design using survey methodology was employed. Of the revised sample, 63 of 120 questionnaires were returned by occupational therapists and speech-language pathologists from 49 California rehabilitation facilities. Many of the findings are limited in the generalization only cautiously to the occupational therapy and speech-language pathology populations of 
California due to the sample including self-selected OTs and SLPs from each facility surveyed which introduced subject bias.

The research questions posed in this study were answered as follows: What are the demographics of the occupational therapists and speechlanguage pathologists surveyed? The sample of OTs and SLPs surveyed represented predominantly full-time employees in the 25 to 34 years age range, averaging 10 years experience in clinical practice and reporting 1 to 5 years of employment at their current setting. The average number of OTs reported working at the respondents' current settings was 10 , whereas the average number of SLPs reported working at the respondents' current settings was 6 . Lastly, the majority of OTs and SLPS (55.6\%) achieved their professional education at colleges or universities located in California.

What are the educational levels and backgrounds of the occupational therapists and speech-language pathologists surveyed? The educational levels and backgrounds of the OT and SLP respondents revealed a number of discrepancies between the two groups. While only $18 \%$ of OTs reported achieving an M.A.M.S. as their highest degree, $97 \%$ of SLPs reported achieving an M.A.M.S. and 3\% a Ph.D. as their highest educational degree. This is largely due to the fact that SLPs are required to have a master's degree for entry into the profession, while OTs are required to have only a bachelor's degree.

Another notable discrepancy found is that a significant number of SLPS received no training for dysphagia case management in their college courses whereas only $3 \%$ of OTs reported receiving no swallowing curriculum in college. On the other hand, $20 \%$ of SLP respondents reported receiving 10 or 
more hours of college course work in dysphagia management and the majority of OT respondents (69\%) reported receiving 1 to 5 hours of swallowing course work in college. These results indicate a strong representation of OT colleges, predominantly in California, which provided a minimal base of knowledge in the area of dysphagia intervention and a large number of SLP colleges throughout the United States who provided no dysphagia content in their curricula. This is consistent with Mody and Nagai's (1990) findings that, at least in Southern California colleges, dysphagia management has not been well represented in the OT or SLP curricula.

Both the OTs and SLPs reported developing their skills in dysphagia intervention most frequently through continued education courses and their current place of employment. Although a considerable number of OTs attended continued education courses to further develop their skills in dysphagia management, they were not well represented in the reported role delineations for primary dysphagia intervention, such as performing bedside swallowing evaluations and videofluoroscopies.

Do C.A.R.F. accredited and/or N.A.R.F. membered California rehabilitation facilities utilize an interdisciplinary team approach to dysphagia intervention? The results indicated that although over half of the California rehabilitation facilities surveyed reported speech-language pathology as the primary discipline in dysphagia case management, $39 \%$ reported that their facilities utilize an OT/SLP interdisciplinary team approach with dysphagia cases. Although these findings may reflect the strong representation the profession of SLP continues to demonstrate in the clinical, educational, and research realms of dysphagia rehabilitation, they also may demonstrate a move toward 
increased interdisciplinary relations between OT and SLP in dysphagia management.

How do these facilities delineate the roles of the occupational therapists and speech-language pathologists in the evaluation and intervention of dysphagia? The results indicated that many of the roles involved in dysphagia management were shared by OT and SLP (reported as "jointly" where both disciplines perform the role or "either" where either discipline can perform the role). These findings supported the current literature's claim that there is movement toward increased interdisciplinary or transdisciplinary roles and frameworks in rehabilitation settings.

For the facilities which do not follow an OT/SLP team approach to dysphagia, the most notable exceptions to the reported role sharing were speech-language pathology's primary involvement in bedside dysphagia evaluations, videofluoroscopies, oral-facial exercises, diet upgrades, family training, and thermal stimulation and occupational therapy's primary responsibility for self-feeding retraining and postural positioning. These delineations reflect much of the multidisciplinary literature's descriptions of traditional OT and SLP roles in dysphagia management where SLP is responsible for primary dysphagia services and OT brings its skills in selffeeding components and positioning to the patient.

Is there a perception of role conflict or role consonance among the occupational therapists and speech-language pathologists surveyed? Role consonance or harmony versus role conflict or territorialism was clearly expressed by the OT and SLP respondents as predominant in their interdisciplinary relations involving dysphagia case management. The reported 
existence of role harmony was equal for those OTs and SLPs who did and who did not follow an interdisciplinary team approach to dysphagia and therefore cannot be correlated with the presence of the team approach. Acceptance that one discipline (OT or SLP) has more expertise in the area of dysphagia and acceptance that each discipline brings its unique skills and knowledge to the management of dysphagic patients were the most commonly reported factors contributing to role harmony between OTs and SLPs.

In contrast, for those OTs who reported the existence of role conflict or territorialism, philosophic differences regarding role delineation, threat of loss of professional role, and staffing issues were the most commonly expressed contributing factors. The SLP respondents also reported philosophic differences and threat of loss of professional role as well as conflicting case management strategies and lack of knowledge/exposure to the other disciplines as the most common contributing factors to role conflict. Edward and Hanley (1989) also found staff shortage to be an interfering factor in interdisciplinary relations between OTs and SLPs but philosophic differences regarding role delineation and conflicts regarding case management strategies were reported as only minimally limiting to meaningful interdisciplinary activity.

Is an interdisciplinary approach to dysphagia perceived to be of value for intervention? A large percentage of OT and SLP respondents reported their interdisciplinary relations in the area of dysphagia intervention to be very valuable or moderately valuable. These results are consistent with Edwards and Hanley's (1989) findings that $91 \%$ of SLPs and $89 \%$ of OTs found their professional contacts with each other to be valuable. In addition, of the numerous reasons reported, concern for improving the quality of care to their 
patients was the factor most frequently attributed to valuable interdisciplinary OT/SLP relations in dysphagia case management. Only six respondents attributed minimal to no value to their OT/SLP interdisciplinary relations in the area of dysphagia intervention.

Additional data which was not addressed in the research questions but was found to be relevant included reported documentation practices and issues pertaining to differentiating OT/SLP roles in dysphagia management for reimbursement purposes. Of the 35 facilities which responded to this question, $40 \%$ reported developing specific documentation practices for reimbursement of dysphagia services, 9 of whom reported delineating roles such as swallowing therapy for SLP and self-feeding and positioning for OT. These role delineations may be in response to increased adherence to reimbursement guidelines. Allen, Foto, Moon-Sperling, and Wilson (1989) described reasons for Medicare denial of coverage. One of these reasons involved duplication of services. They stated if a single discipline, such as occupational therapy, physical therapy, or speech-language pathology, can provide the care, only one discipline can bill the charges. They also emphasized that "senices are not considered duplicative in cases where both services involved have unique treatment goals that lead to distinct functional goals" (p. 796). When asked if reimbursement issues had arisen in the area of dysphagia services, only $5 \%$ of the 37 facilities answered yes, citing duplicable services between OT and SLP in the area of videofluoroscopic swallow studies as the example.

Another relevant finding described areas of unique expertise which the OT and SLP respondents felt their discipline contributed to the interdisciplinary team approach to the dysphagic patient. One-hundred percent of the 22 SLP 
respondents reported both knowledge of oral, pharyngeal, and esophageal structures and function and knowledge of normal and disordered swallowing and its evaluation and treatment as unique areas of their discipline's expertise. In contrast, less than half of the 32 OTs reported the above areas of unique expertise to be part of what their discipline brings to the interdisciplinary team approach to patients with dysphagia. These findings suggest that over half of the OTs surveyed do not consider swallowing anatomy, physiology, and dysfunction to be unique areas of knowledge within the realm of their profession which contribute to the dysphagia team approach. On the other hand, the OT respondents overwhelming considered knowledge of self-feeding skill components, functional positioning techniques, and cognitive and visual perceptual skills/deficits as areas of unique expertise which their discipline contributes to the dysphagia team approach.

\section{Professional Implications}

As the incidence of swallowing disorders in adult populations increases, the need to assess occupational therapy's current and future role in dysphagia management becomes strikingly evident. As evidenced by their wealth of clinical research and literature in the area of dysphagia, the profession of speech-language pathology is meeting this increase of dysphagia cases with much focus and fervor.

Although this study demonstrates the growing trend of OT/SLP interdisciplinary team relations in the management of adults with dysphagia, it also underscores the growing role speech-language pathology is initiating in the primary management of dysphagia cases. The American SpeechLanguage-Hearing Association (ASHA) has greatly surpassed the American 
Occupational Therapy Association (AOTA) in producing specific educational requirements, clinical competency standards and role descriptions for SLPS providing services to dysphagic patients/clients (1990).

As reimbursement pressures increase from third party payors to prevent overlapping of roles, the need to delineate OT and SLP professional roles in dysphagia management becomes inevitable. In keeping with the inclusion of "eating" as an activity of daily living which OT has a primary role in treating, the profession of occupational therapy will need to focus much more intensively on clarifying and developing this role. If the profession of occupational therapy neglects to do so, their role in the intervention of dysphagia may become more limited and restricted over time. As evidenced by this study and by the existing allied health literature, these limitations are already developing with occupational therapy's role in dysphagia intervention becoming confined to self-feeding and positioning.

\section{Conclusions}

As evidenced by this study and by Edwards and Hanley's (1989) study, the interdisciplinary relations between occupational therapy and speech-language pathology are for the most part perceived as positive, valuable, and of benefit to patient care. The role conflict or territorialism reported by the remaining OT and SLP respondents is cause for continued concern and discussion. As emphasized by Bassoff (1983), with the move toward some form of national health insurance, "the call for 'comprehensiveness' of care mandates the development of stronger collaborative relationships among the health disciplines" (p. 281). To meet this mandate, she advocated that different allied health disciplines share educational experiences at the student level prior to 
beginning clinical practice. Harris, Saunders, and Zasorin-Connors (1976) recommended the following content areas to be included in interdisciplinary health care courses: Team models, roles of various health care professionals, and group process and communication across professional boundaries. While the curricula of occupational therapy college programs includes teaching a commitment to values and ethics of its own profession, it generally fails to provide requisites for interdisciplinary practice such as education on the roles of its professional colleagues and the unique interdependency of clinical practice among multidisciplines.

In 1986, AOTA sought to explore dysphagia issues and concerns in conjunction with ASHA with the advent of the Joint Ad Hoc Committee. This committee set long-term plans to perform collaborative research in dysphagia and improve clinical expertise among members (Mody \& Nagai, 1990). Although no further published information was found updating the status of these plans, this interdisciplinary collaboration is a positive step toward addressing the need to assess current professional roles and conduct research in the area of dysphagia. Perhaps the more exposure and positive collaborations we share with the profession of speech-language pathology, the more value and role harmony will be experienced in our growing transdisciplinary relations. The profession of occupational therapy could strongly benefit from future clinical, professional, and interdisciplinary explorations and research into the intervention and case management of adults with dysphagia. 


\section{REFERENCES}

Allen, C., Foto, M., Moon-Sperling, \& Wilson, D. ((1989). A medical review approach to medicare outpatient documentation. The American Journal of Occupational Therapy, 43, 793-800.

American Occupational Therapy Association. (1986). Reference manual of the official documents of the American Occupational Therapy Association, Inc. Maryland: The American Occupational Therapy Association, inc.

American Occupational Therapy Association, Commission on Practice. (1989).

Occupational therapy and eating dysfunction (position paper). The American Journal of Occupational Therapy, 43, 805.

American Speech-Language-Hearing Association, Task Force on Dysphagia. (1990). Knowledge and skills needed by speech-language pathologists providing services to dysphagic patients/clients. American SpeechLanguage-Hearing Association, 32, 7-12.

American Speech-Language-Hearing Association. (1990). Scope of practice, speech-language pathology and audiology. American Speech-LanquageHearing Association, 32, 1-2.

Avery-Smith, W., \& Dellarosa, D. (1994). Approaches to treating dysphagia in patients with brain injury. The American Journal of Occupational Therapy, 48, 235-239.

Avery-Smith, W., Dellarosa, D, \& Rosen, A. B. (1992). Clinical assessment of dysphagia in adults. Occupational Therapy Practice, $\underline{3}(2), 51-58$.

Bach, D. B., Pouget, S., Belle, K., Kilfoil, M., Alfieri, M., McEvoy, J., \& Jackson, G. (1989). An integrated team approach to the management of patients with oropharyngeal dysphagia. Journal of Allied Health, 18, 459-468. 
Bair, J. (1983). Nationally speaking, programmatic treatment. The American Journal of Occupational Therapy, 37, 11-13.

Bassoff, B. Z. (1983). Interdisciplinary education as a facet of health care policy: The impact of attitudinal research. Journal of Allied Health, 12, 280-286.

Boggis, T. (1985). Dysphagia management of the adult comatose head trauma patient. Physical Disabilities Special Interest Section Newsletter, $8(3), 1-4$.

Cherney, L. R., Cantieri, C. A., \& Pannell, J. J. (1986). Clinical evaluation of dysphagia. Rockville, MD: Aspen Publishers.

Cloke, H., \& Miller, L. (1989). Dysphagia in the traumatically brain injured patient. Physical Disabilities Special Interest Section Newsletter, 12(3), 4-5.

Cromwell, F. S. (Ed.). (1986). Occupational therapy for people with eating dysfunctions. New York: Haworth Press.

Darling, L. A., \& Ogg, H. L. (1984). Basic requirements for initiating an interdisciplinary process. Physical Therapy, 64, 1684-1686.

Donner, M. W. (Ed.). (1986). Editorial. Dysphagia, 1, 1.

Edwards, S., \& Hanley, J. (1989). Interdisciplinary activity between occupational therapists and speech language pathologists. Journal of Allied Health, 18 , 375-387.

Emick-Herring, B., \& Wood, P. (1990). A team approach to neurologically based swallowing disorders. Rehabilitation Nursing, 15, 126-132.

Enstrom, D. H., Fleming, S. M., Johns, D. F., Larkins, P. G., Perlman, A. L., Robbins, J., Sonles, B. C., Weinberg, B., \& Logemann, J. A. (1987). Ad hoc committee on dysphagia report. American Speech-Language Hearing Association, 29(4), 57-58. 
Erlichman, M. (1989). Public health service assessment: The role of speech language pathologist in the management of dysphagia, 1989. Health Technology Assessment Reports, 1, 1-10.

Glenn, N. H., Araya, T. B., Jones, K. G., \& Liljefors, J. (1993). A therapeutic feeding team in the rehabilitation setting. Holistic Nursing Practice, 7(4), 73-81.

Groher, M. E. (1984). Dysphagia: Diagnosis and management. Massachusetts: Butterworth's.

Harris, J. L., Saunders, D. N., \& Zasorin-Connors, J. (1976). A training program for interprofessional health care teams. Health and Social Work, 3 , 35-53. Hynak-Hankinson, M. T., Agin, M., Gardner, C., Jones, P. L., Lichtenstein, S., Peiffer, S., \& Rao, P. (1984). Dysphagia evaluation and treatment: The team approach, part 1. Nutritional Support Services, 4(5), 33-41.

Hynak-Hankinson, M. T., Agin, M., Gardner, C., Jones, P. L., Lichtenstein, S., Peiffer, S., \& Rao, P. (1984). Dysphagia evaluation and treatment: The team approach, part 2. Nutritional Support Services, 4(6), 30-33.

Ivey, S., Brown, K. S., Teske, Y., \& Silverman, D. (1988). A model for teaching about interdisciplinary practice in health care settings. Journal of Allied Health, 17(3), 189-195.

Jones, P. L., \& Altschuler, S. L. (1987). Dysphagia teams: A specific approach to a non-specific problem. Dysphagia, 1, 200-205.

Kielhofner, G. (1983). Health through occupation, theory and practice in occupational therapy. Philadelphia: FA Davis Co.

Logemann, J., \& Bytell, D. (1979). Swallowing disorders in three types of head and neck surgical patients. Cancer, 44, 1095-1105. 
Logemann, J. (1983). Evaluation and treatment of swallowing disorders.

San Diego, CA: College-Hill Press.

Logemann, J. (1985). Manual for the videofluoroscopic examination of

dysphagia. San Diego, CA: College-Hill Press.

Logemann, J. (1986). Treatment for aspiration related to dysphagia: An

overview. Dysphagia, 1, 34-38.

Logemann, J. (1987). Criteria for studies of treatment for oral-pharyngeal dysphagia. Dysphagia, 1, 193-199.

Logemann, J. (1989). Challenges for the speech-language pathologist working in dysphagia. Hearsay, Journal of the Ohio Speech and Hearing Association, 6-10.

Logigian, M. K. (Ed.). (1982). Adult rehabilitation: A team approach for therapists. Boston: Little, Brown, and Company.

Lorman, J. S. (1989). Development of dysphagia program at Akron City Hospital. Hearsay, Journal of the Ohio Speech and Hearing Association, 11-13.

Lubinski, R., \& Frattali, C. (1993). Nursing home reform. American Speech-Lanquage-Hearing Association, 35(1), 59-62.

Martens, L., Cameron, T., \& Simonsen, M. (1990). Effects of a multi-disciplinary management program on neurologically impaired patients with dysphagia. Dysphagia, $\underline{5}, 147-151$.

Miller, R. M., \& Groher, M. E. (1993). Speech-language pathology and

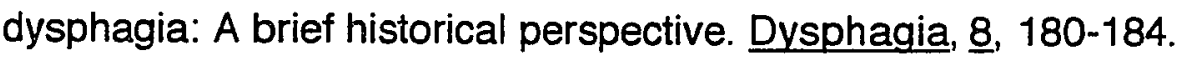


Mody, M., \& Nagai, J. (1990). A multidisciplinary approach to the development of competency standards and appropriate allocation for patients with dysphagia. The American Journal of Occupational Therapy, 44, 369-372.

Penington, G. R., \& Krutsch, J. A. (1990). Swallowing disorders: Assessment and rehabilitation. British Journal of Hospital Medicine, 44(1), 17-22.

Rood, M. S. (1956). Neurophysiological mechanisms utilized in the treatment of neuromuscular dysfunction. American Journal of Occupational Therapy, 10, 220-225.

Roueche, J. R. (1980). Dysphagia: An assessment and management program for the adult. Minneapolis: Sister Kenny Institute.

Silverman, E. H., \& Enfant, I. L. (1979). Dysphagia: An evaluation and treatment program for the adult. American Journal of Occupational Therapy, 33, 382-392.

Stallons, K. M. (1987). The evaluation and treatment of swallowing disorders. Physical Disabilities Special Interest Section Newsletter, 10, 4-5.

Stein, J., Hauck, L. C., \& Su, P. Y. (Eds.). (1984). The random house college dictionary. New York: Random House, Inc.

Travis, L. E. (1931). Speech Pathology. New York: Appleton.

Yuen, H. K., \& Hartwick, J. A. (1992). Diet manipulation to resume regular food consumption for an adult with traumatic brain injury. The American Journal of Occupational Therapy, 46, 943-945. 
APPENDIX A QUESTIONNAIRE 


\section{QUESTIONNAIRE}

Please check box: $\quad$ Occupational therapist $\quad$ OOther $\checkmark$ Speech-language pathologist

1) Where do you currently practice?

2) Do you work full time or part time?

3) State your age.

4) How long have you been practicing in your profession?

5) How long have you been at your current job?

6) How many OTs are employed at your setting? SLPS?

7) Which is the highest level of education you have achieved?
a. B.A./B.S.
b. M.A.M.S.
c. Ph.D.
d. other:

8) State the name and state of the college where you received your O.T. or S.L.P. education

9) Do you have professional skills to evaluate and treat patients with dysphagia? Please circle: Yes or No

10) Which of the following places did you develop skills in dysphagia management? Circle all that apply.
a. College
b. Internships
c. Continued education courses
d. Past place/s of employment
e. Current place of employment 
11) Approximately how many hours of training in the area of dysphagia intervention did you receive in college, if any? (excluding internships)
a. 80 or more hours
b. 40 to 60 hours
c. 10 to 20 hours
d. 5 to 10 hours
e. 1 to 5 hours
f. none

12) Which of the following diagnoses does your facility admit? Circle all that apply.
a. C.V.A.
b. T.B.I.
c. S.C.I.
d. Head and Neck CA
e. Parkinson's Disease
f. A.L.S.
g. Guillain Barre
h. All of the above

13) If there are any of the above diagnoses of which O.T. or S.L.P. is the sole provider of dysphagia intervention, please list next to the appropriate discipline:

O.T.

S.L.P.

14) Which discipline is responsible for the primary evaluation and treatment of the patients with dysphagia?
a. Speech-language pathology
b. Occupational therapy
c. Physical therapy
d. O.T. and S.L.P. interdisciplinary team approach
e. Other:
f. No intervention provided 
15) Does any territorialism or role conflict exist between the OTs and SLPs in the area of dysphagia management?

Please circle: Yes or No

If no then skip to \#17.

16) Which of the following factors do you feel contributes to this conflict:

Circle all that apply.

a. Philosophical differences re: role delineation

b. Problems or conflicts re: case management strategy

c. Staffing issues

d. Personality conflicts with interdisciplinary colleagues

e. Threat of loss of professional role in the area of dysphagia

f. Threat of loss of current position

g. Lack of knowledge of or exposure to other disciplines

h. Other:

17) If no role conflict exists between the OTs and SLPs in the area of dysphagia, what factors do you think contribute to the role consonance or harmony?

a. Acceptance that one discipline (OT or SLP) has more expertise in the area of dysphagia.

b. Acceptance that each discipline brings its unique skills and knowledge to the management of dysphagic patients.

c. Our facility has an OT/SLP team approach to dysphagia which creates more constructive exposure to the other discipline.

d. Perception that the dysphagic patients benefits from OT/SLP team approach even if the roles overlap.

e. The roles of OT and SLP are well differentiated in the management of dysphagia.

f. Other:

18) If your facility does not have an OTISLP interdisciplinary team approach toward dysphagia, would you like to see one developed? Please circle: Yes or No 
If an O.T./S.L.P. team approach to dysphagia exists in your facility, please answer the following questions:

19) How long has this program been in existence?

20) What factors contributed to the development of this team approach? Circle all that apply.

a. Departmental policy

b. The specific dysphagia intervention skills of the OTs and SLPs

c. Research or studies advocating the benefits of a team approach

d. Staff recommendations

e. Other:

21) Please circle the appropriate discipline(s) which correspond(s) to the delineated role or area of patient training:

Bedside dysphagia evaluations: $\quad$ OT SLP Either Jointly Other

Videofluoroscopies: $\quad$ OT SLP Either Jointly Other

Feeding/Meal groups: $\quad$ OT SLP Either Jointly Other

Thermal stimulation: $\quad$ OT SLP Either Jointly Other

Oral-facial exercises: $\quad$ OT SLP Either Jointly Other

Self-feeding retraining: $\quad$ OT SLP Either Jointly Other

Compensatory head techniques: OT SLP Either Jointly Other

Postural positioning: $\quad$ OT SLP Either Jointly Other

Diet upgrades: $\quad$ OT SLP Either Jointly Other

Family training in dysphagia OT SLP Either Jointly Other intervention: 
22) What area of unique expertise do you feel your discipline has that enhances the team approach to the dysphagic patient? Circle all that apply.
a. Knowledge of oral, pharyngeal, laryngeal, and esophageal structures and function
b. Knowledge of normal and disordered swallowing and its evaluation and treatment
c. Knowledge of normal anatomy and physiology of speech structures and processes
d. Knowledge of overall sensory-motor control and function
e. Knowledge of functional positioning techniques
$\mathrm{f}$. Knowledge of cognitive and visual perceptual skills/deficits
g. Knowledge of psychosocial components
h. Knowledge of self-feeding skill components

23) Have your departments developed specific documentation practices to differentiate OT/SLP roles in dysphagia management for reimbursement purposes? If so, what are they?

24) Have reimbursement issues arisen regarding duplicable services between OT and SLP in the area of dysphagia evaluation and treatment? Please circle: Yes No If so, what are these issues?

25) Please circle the measure of value you attribute to your interdisciplinary relations with OT or SLP in area of dysphagia:

Very valuable Moderately valuable Minimally valuable No value

26) Please list the reasons you think your interdisciplinary relations with OT or SLP in the area of dysphagia are valuable or not valuable 
APPENDIX B

\section{LETTER OF CONSENT}


College of Applied Sciences and Arts - Department of Occupational Therapy One Washington Square • San José, California 95192-0059

Main Office: 408/924-3070 • Fieldwork Office: 408/924-3078 • FAX: 408/924-3088

\section{AGREEMENT TO PARTICIPATE IN RESEARCH AT SAN JOSE STATE UNIVERSITY}

Responsible Investigator: Frieda Weiss, O.T.R., Clinical Specialist, Mount Zion Hospital of the University of California, San Francisco.

Title of Study: A survey of interdisciplinary activity between occupational therapists and speech-language pathologists in the evaluation and treatment of adults with dysphagia.

I have been asked to participate in a research study that is investigating the interdisciplinary activities and relations between occupational therapists (OT) and speech-language pathologists (SLP) in the evaluation and treatment of adults with dysphagia. The results of this study should further our understanding of the frequency, quantity, and quality of occupational therapy/speech-language pathology interdisciplinary interactions in the case management of patients with dysphagia. It is hoped that the information generated will heip to identify issues, questions, and resolutions related to the overlapping of roles among disciplines in the intervention of dysphagia among adult populations.

I understand that

1) I will be asked to complete a questionnaire which addresses the above topic.

2) the possible benefits of this study to me are an increased awareness of the value and/or issues which may exist with an OT/SLP interdisciplinary approach toward dysphagia.

3) the results from this study may be published, but any information from this study that can be identified with me will remain confidential and will be disclosed only with my permission or as required by law. 
4) any questions about my participation in this study will be answered by Frieda Weiss at (415) 751-4060. Complaints about the procedures may be presented to the following at San Jose State University (SJSU), Department of Occupational Therapy: Dr. Gordon U. Burton, my thesis advisor, at (408) 924-3074 or Dr. Lela Llorens, Department Chair at (408) 924-3072. For questions or complaints about research subject's rights, or in the event of research-related injury, contact Serena Stanford, Ph.D., Associate Academic Vice President for Graduate Studies at (408) $924-2480$.

5) my consent is given voluntarily without being coerced; I may refuse to participate in this study or in any part of this study, and I may withdraw at any time, without prejudice to my relations with SJSU.

6) I have received a copy of this consent form for my file.

I HAVE MADE A DECISION WHETHER OR NOT TO PARTICIPATE. MY SIGNATURE INDICATES THAT I HAVE READ THE INFORMATION PROVIDED ABOVE AND THAT I HAVE DECIDED TO PARTICIPATE.

\section{Date}

SUBJECT'S SIGNATURE

INVESTIGATOR'S SIGNATURE 


\section{APPENDIX C}

INTRODUCTORY LETTER 
80 Seventh Ave. \#9

San Francisco, CA

94118

(415) $751-4060$

Dear Department Managers of Occupational Therapy and Speech-Language Pathology,

I am a registered occupational therapist who currently works in an acute rehabilitation facility with adult populations. I am writing this letter to request your participation in a research study for my Master's Thesis. The study involves a survey of interdisciplinary activity between occupational therapists (OT) and speech-language pathologists (SLP) in the evaluation and treatment of adults with dysphagia. I will be sending out the attached questionnaires to N.A.R.F. members and/or C.A.R.F. accredited rehabilitation facilities throughout California. The results of this study should further our understanding of the frequency, quantity, and quality of occupational therapy/speech-language pathology interactions in the case management of patients with dysphagia. It is hoped that the information generated will help to identify issues, questions, and resolutions related to the overlapping of roles among disciplines in the interventions of dysphagia among adult populations. 
Please ask for one volunteer from each of your prospective departments (1 OT \& 1 SLP total) to participate in completing the attached questionnaires. The questionnaire contains multiple choice, rank-scale, and open-ended questions. Please send me the completed questionnaires in the enclosed prestamped and addressed envelopes by September 15, 1993. Thank you so much for your time, interest, and participation.

Sincerely,

Frieda Weiss, O.T.R. 
APPENDIX D

POSTCARD REMINDER 
Frieda Weiss

80 Seventh Ave. \#9

San Francisco, CA

94118

Attn: Occupational Therapy and Speech-Language Pathology Departments

Dear OT and SLP Departments,

Just a reminder to please complete and send the questionnaires you received which addressed OT/SLP interdisciplinary relations and roles in the area of dysphagia management.

I greatly appreciate your time and interest.

Thank you, $\quad$ Frieda Weiss, O.T.R. 